\title{
COMER NÃO SIGNIFICA MATAR A FOME
}

\author{
Uesley Henrique Zaia ${ }^{1}$ \\ Katarzyna Bortnowska ${ }^{2}$
}

\section{INTRODUÇÃO}

A população mundial acima de 65 anos atingiu $8 \%$ da população total em 2012 e em 2015 estava em 8,5\%, entre os anos 2025 a 2050, a população mais idosa está projetada para dobrar enquanto a população total crescerá apenas 34 por cento no mesmo período (HE, GOODKIND E KOWAL, 2016). Segundo a United Nation (2016), o Brasil é a quinta nação mais populosa do mundo, com mais de 200 milhões de habitantes. Conforme Lima-Costa et al (2016: 1349) "6,5 milhões de brasileiros com 60 anos ou mais precisam de ajuda para realizar atividades da vida diária, em que 360.000 não receberam ajuda, embora precisassem”.

Esse fator implica em uma mudança na cultura de saúde de um país, por exemplo: idosos adoecem com mais frequência, ao invés de processos agudos com alta resolubilidade através da cura ou do óbito, tornam-se predominantes as doenças crônicas e suas complicações, que implicam em décadas de utilização dos serviços de saúde. Assim deve se estar preparado para atender essa população bem como as doenças que se manifestam com a idade: Alzheimer, Parkinson, demência senil e todas as complicações que as acompanham (CHAIMOWICZ, 1997). Neste sentido, a população brasileira tem um desafio pela frente para garantir a qualidade das Instituições de Longa Permanência para os Idosos -ILPIs (LIMA-COSTA et al, 2018).

Assim, surge a preocupação da comunidade científica com a qualidade de vida da população idosa. A constatação das doenças condicionam a modificação de todas as situações do cotidiano, de um idoso, doenças como Alzheimer, Parkinson podem acarretar em um distúrbio de deglutição, chamado clinicamente de disfagia, ou seja, na presença de tal condição hábito outrora agradável, e considerado até então natural como a alimentação, passa a ser doloroso e constrangedor, sendo que, na maioria das vezes

\footnotetext{
${ }^{1}$ Faculdade Estácio de Florianópolis, Brasil. Email: bortnowska@yahoo.com ORCID id: https://orcid.org/0000-0001-6676-3332

${ }^{2}$ Faculdade Estácio de Florianópolis, Brasil. Email: uhzaia87@gmail.com ORCID id: https://orcid.org/0000-0003-3253-7059
} 
essas restrições assumem um caráter negativo, transformando um hábito tão valorizado em nossa cultura em um momento de isolamento social (SOUZA et al., 2003).

Não obstante, o ato de comer é provavelmente uma das primeiras atividades aprendidas na infância e uma das últimas a se perder com a senescência, em relação a tal aspecto outro fator que está diretamente relacionado a atividade alimentar do idoso são as diminuições da sensibilidade dos órgãos dos sentidos, ou seja, a senilidade dos cinco sentidos, que podem ser agravados também na condição de uma doença degenerativa, como as já citadas anteriormente. Com esses declínios todo o composto da alimentação sofre mudanças de acordo com o ambiente que o idoso está inserido, pois sabe-se, que todo o contexto de ambiente exerce influência, auxiliando assim na manutenção da competência do idoso.

A esse respeito Oliveira, Veras e Prado (2010:133) abordam que "apesar dos avanços recentes nos campos da Geriatria e Gerontologia e da Alimentação e Nutrição no Brasil, ainda são raros os estudos qualitativos situados no encontro dessas áreas". Verifica-se então uma escassez de pesquisas sobre a percepção da alimentação dos idosos com disfagia, justificando o presente estudo como uma ferramenta de auxílio ao processo nutricional desses idosos, sabendo que é consensual que doenças como demência associadas a disfagia compromete a qualidade de vida do paciente idoso (PIVI, SCHUULTZ E BERTOLUCCI, 2013), entretanto é preciso enxergar a alimentação como algo além do nutricional, é igualmente importante entender a alimentação como atividade repleta de significações, que fornece conforto e inseridos socialmente aqueles, que em um passado recente, só lhes restava o isolamento social e a espera passiva pelo fim da vida.

Convém, no entanto, esclarecer o objetivo desse trabalho mediante as informações supracitadas que é analisar as percepções dos cinco sentidos em pacientes com disfagia, através de relatos dos colaboradores de uma Instituição de Longa Permanência para Idosos (ILPIs) na Grande Florianópolis, SC.

Assim se explanará nesse trabalho o conceito de disfagia, as doenças a ela relacionadas, a perda das ações cognitivas relacionadas ao idoso e a importância da alimentação correta para esses pacientes. Acredita-se que este trabalho se apresenta como um desafio motivador tanto para este acadêmico, quanto para qualquer interessado na gastronomia que vai além dos restaurantes buscando sobretudo uma aplicação prática da teoria vista em sala de aula durante o curso de graduação. 


\section{DISFAGIA}

A deglutição ou propriamente dito o ato de alimentar-se depende de aspectos sociais, econômicos, culturais, religiosos, dessa forma, por meio dele obtêm-se referências consistentes das tradições e costumes alimentares de um povo (SOUZA et al., 2003). Pivi, Schuultz e Bertolucci (2013:14), relataram que "o ato de comer é fundamental para a vida. Na cultura de todos os povos o homem manifesta a sua cultura e história através das práticas alimentares, desde a preparação ao consumo”. De um ponto de vista mais clínico, a alimentação é o processo responsável por manter os indivíduos nutridos e hidratados, ou seja, clinicamente saudáveis (FURKIM; SACCO, 2008,).

De acordo com Pivi, Schuultz e Bertolucci (2013), o comprometimento do estado nutricional dos seres humanos está relacionado com as alterações comportamentais que dificultam sua alimentação, sendo um desses comprometimentos chamados de disfagia. Na mesma linha de pensamento "distúrbios no processo da deglutição podem causar problemas na alimentação, sendo estes transtornos chamados de disfagia” (FURKIM; SACCO, 2008: 02).

"Disfagia é qualquer dificuldade na efetiva condução do alimento da boca até o estômago por meio das fases inter-relacionadas, comandadas por um complexo mecanismo neuromotor" (MYRIAN NAJAS, 2011: 04). De um ponto de vista mais conciso:

De maneira geral, a disfagia é um sintoma de outra condição de ordem neurológica, psicogênica, estrutural ou mecânica ou por mudanças fisiológicas que ocorrem na senilidade. É condição muito frequente em pacientes com doenças de Alzheimer e Parkinson. Pode também ser secundária ao uso de alguns medicamentos como neurolépticos, corticoides, anticolinérgicos ou benzodiazepínicos (MYRIAN NAJAS, 2011: 198).

A disfagia ainda pode ser descrita como o ato de dificuldade de preparação oral do alimento ou como a falha do simples movimento de levar alimento ou saliva ao estômago (PAGNO, 2009).

Todo esse problema ocorre devido a mesma origem embriológica do sistema respiratório e digestório, de forma que os mesmos aparelhos compartilham das mesmas vias de acesso (SOUZA et al., 2003). Conforme Lewis, Liss e Sciortino (2009: 01), “o culpado é o grande espaço supralaríngeo criado pela posição baixa da laringe humana 
do adulto, no pescoço. Esse espaço funciona como via comum para a respiração, a deglutição (o ato de engolir), e a modulação das ondas sonoras que produzem a fala".

Não obstante, ainda esse mecanismo nos diferencia de outros mamíferos, cujo aparelhos respiratório e de deglutição são separados, uma vez que a laringe ocupa uma posição acima do pescoço e boca (LEWIS; LISS; SCIORTINO, 2009).

Disfagia ainda pode ser dividida em orofaríngea caracterizada por uma lesão acima do esôfago, resultando em problemas de transferência do alimento da boca à faringe e esôfago, outra divisão é a esofagiana ou esofágica onde o problema é de transporte do bolo alimentar já formado entre a faringe e o esôfago (SOUZA et al., 2003: 09). Sendo que são diferentes as alterações ocasionadas pelas duas, como demonstrado no quadro 1.

Quadro 1 - Alterações ocasionadas entre disfagia orofaríngea e esofagiana

\begin{tabular}{|c|c|}
\hline Orofaríngea & Esofagiana \\
\hline Dificuldade de fechamento dos lábios & $\begin{array}{l}\text { Déficit de motilidade da musculatura esofagiana, } \\
\text { que causa alteraçoes na Peristalse ou Acalasia }\end{array}$ \\
\hline$>$ Dificuldade de mastigação & $>$ Disfunção do esfíncter esofagiano inferior \\
\hline$>$ Motilidade alterada na língua & $>$ Obstrução do lúmen do esôfago \\
\hline$>$ Redução da força propulsora da língua & $>$ Combinação desses problemas \\
\hline $\begin{array}{l}\text { Dificuldade de contenção do bolo alimentar na } \\
\text { boca }\end{array}$ & \\
\hline$>$ Atraso no reflexo de deglutição & \\
\hline$>$ Aumento de tempo de trânsito do bolo alimentar & \\
\hline $\begin{array}{l}\text { Dificuldade na limpeza de resíduos retidos na } \\
\text { faringe }\end{array}$ & \\
\hline $\begin{array}{l}\text { Dificuldade de abertura do esfíncter superior do } \\
\text { esôfago }\end{array}$ & \\
\hline$>$ Fechamento incompleto da laringe & \\
\hline$>$ Penetração de resíduos ao nível das pregas vocais & \\
\hline$>$ Aspiração de resíduos na traqueia & \\
\hline
\end{tabular}

Fonte: Adaptado de SOUZA et al., 2003: 09.

A esse respeito, Lewis; Liss; Sciortino (2009), afirmam que na maioria dos casos de disfagia esofagiana estão presentes sintomas de orofaringe, ocorrendo quase que simultaneamente. Reafirma também a importância de um diagnóstico preciso, através de vídeofluoroscopia, principalmente tratando-se de disfagia esofagiana, lembrando a complexidade funcional do esôfago. Podemos observar na figura $1 \mathrm{em}$ vermelho o processo o caminho normal do alimento da boca até o esôfago em preto o caminho irregular podendo resultar em uma broncoaspiração.

Figura 1 - Processo de deglutição normal e alterada (broncoaspiração de resíduos) 


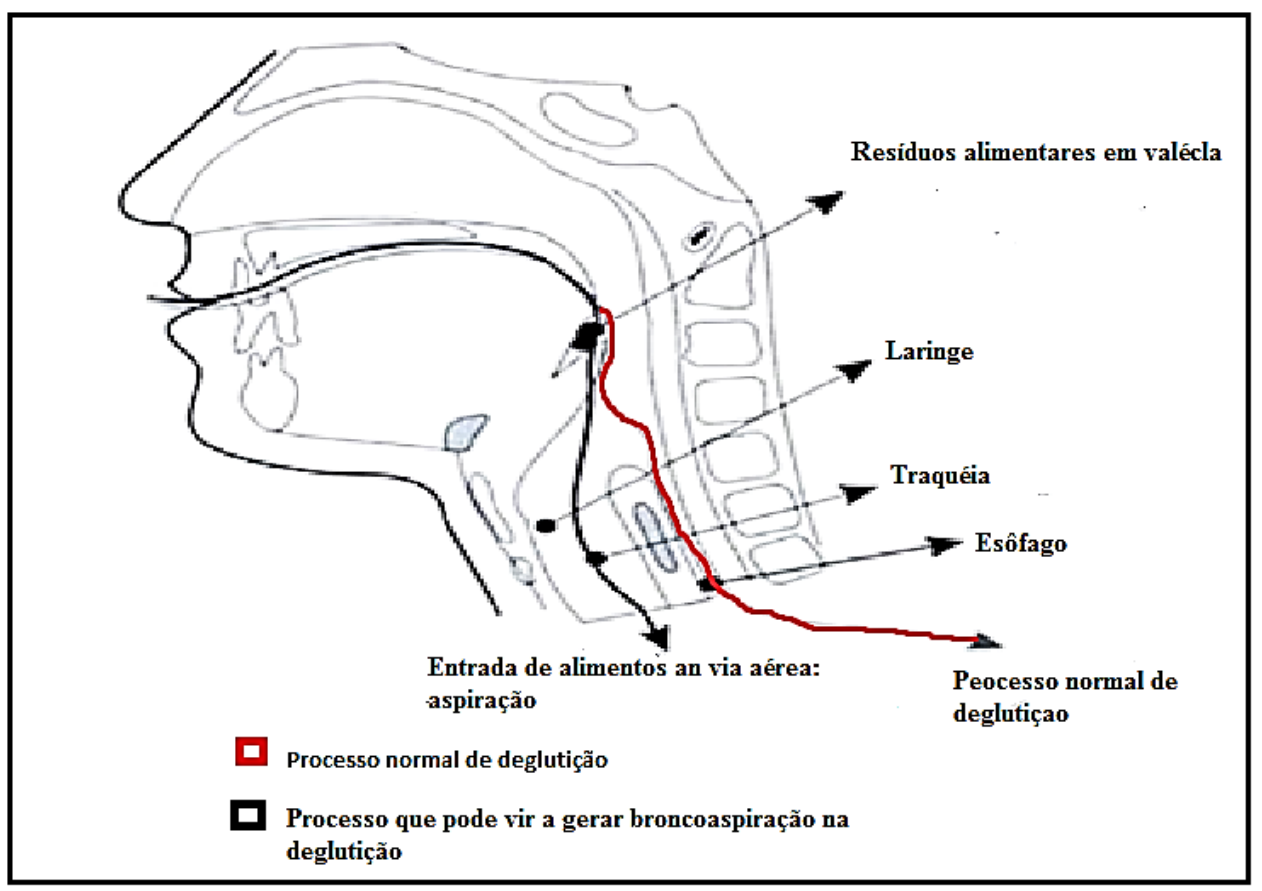

Fonte: SOUZA et al., 2003:10.

"Não há exatidão de datas e locais ou documentos que comprovemos dados, porém autores mencionam como recente a prática específica com disfagia, surgindo em meados dos anos 80, início dos anos 90” (STEIMBERG; FRAZÃO; FURKIM, 2003: 118). Nessa relação Steimberg, Frazão e Furkim (2003: 118), reafirmam que no "período citado acima, o avanço tecnológico e a introdução de exames como videofluoroscopia e videoendoscopia possibilitaram estudos mais profundos sobre a fisiopatologia da deglutição e, logo, melhores abordagens terapêuticas”.

Contudo, é de importância a compreensão de que a disfagia não é uma doença e sim uma condição ou sintoma de uma doença que acometeu qualquer parte do trato digestório, desde a boca até o estomago, que pode estar acompanhado ou não de dor (OLIVEIRA et al., 2008). Por outro lado, como afirma Malagelada et al. (2004),

A disfagia tende a diferir na Europa Ocidental, Américas do Sul e do Norte, sul da Ásia, Oriente Médio e África. Também varia dependendo da idade do paciente e deve ser lembrado que o espectro de doenças que leva a disfagia na infância é diferente do de idosos. Portanto, em escala global só podem ser feitas aproximações. A disfagia ocorre em todas as faixas etárias, mas sua prevalência aumenta com a idade.

"Sendo assim, é essencial reconhecer que a disfagia é um sintoma comum. Geralmente, resultando de uma doença base" (SOUZA et al., 2003: 10).

\subsection{CAUSAS E DOENÇAS COMUNS RELACIONADAS A DISFAGIA}


Na compreensão de Sousa et al. (2003) muitas doenças podem vir a ocasionar um caso de disfagia fora o fato de que pode ocorrer em qualquer idade, sendo criança, jovem, adulto ou idoso, o importante e significativo é saber que essas causas são diferentes entre as idades. Em relação a tal aspecto Pivi, Schuultz e Bertolucci (2013: 66), reafirma que "muitas são as doenças que podem causar disfagia, em especial as doenças neurológicas como as doenças de Parkison e a doença de Alzheimer".

Observa-se que a incidência e a prevalência da disfagia variam de acordo com o grupo estudado: acomete entre $16 \%$ e $22 \%$ da população com mais de 50 anos de idade, alcançando índices de $70 \%$ a $90 \%$ nas populações mais idosas. A disfagia orofaríngea pode ter inúmeras causas, contudo, as doenças de origem neurogênica são as responsáveis pela imensa maioria dos casos: nos pacientes com doença de Parkinson a incidência é superior a 95\%; quanto aos indivíduos que sofreram acidente vascular cerebral (AVC), estima-se que $20 \%$ a $40 \%$ apresentam disfagia(SILVA et al., 2009: 311)

Contemplando as informações citadas as causas mais frequentes estão dispostas no Quadro 2 a seguir:

Quadro2 - Causas frequentes de disfagia

\begin{tabular}{|c|c|}
\hline CRIANÇAS & ADULTOS/IDOSOS \\
\hline Prematuridade & $\begin{array}{c}\text { Doenças neurológicas (acidente vascular cerebral, } \\
\text { Parkinson, Alzheimer, paralisia cerebral, esclerose } \\
\text { múltipla, esclerose lateral amiotrófica, tumores } \\
\text { cerebrais, trauma) }\end{array}$ \\
\hline Anomalias do sistema digestório/respiratório & Doenças motoras (miastenia gravis) \\
\hline $\begin{array}{l}\text { Defeitos congênitos da cavidade oral, laringe, traqueia } \\
\text { e esôfago }\end{array}$ & Distrofias musculares \\
\hline Defeitos anatômicos adquiridos & $\begin{array}{c}\text { Lesões locais (tumores, ressecção cirúrgica da } \\
\text { orofaringe) }\end{array}$ \\
\hline Distúrbios de desenvolvimento neuromotor & Cirurgia da cabeça e pescoço \\
\hline Desordens traumáticas neuromotoras & Demência \\
\hline Privação da alimentação oral por longo prazo & Doenças sistemáticas (AIDS) \\
\hline Problemas respiratórios & Doença da coluna cervical \\
\hline Problemas cardíacos & Efeitos de medicamentos como antidepressivos. \\
\hline Problemas alimentares comportamentais & Mudanças senis no sistema sensório-motor \\
\hline
\end{tabular}

Fonte: Adaptado de SOUZA et al., 2003: 11.

Em suma, de acordo com Padovani et al. (2007: 199), a disfagia,

Pode ser decorrente de traumas de cabeça e pescoço, de acidente vascular encefálico, de doenças neuromusculares degenerativas, de câncer de cabeça e pescoço, de demências e encefalopatias. A disfagia mais frequentemente reflete problemas envolvendo a cavidade oral, faringe, esôfago ou transição esofagogástrica. 
É imperativo ainda ressaltar que algumas doenças se diferenciam entre disfagia orofaríngea e esofagiana. Distúrbios neuromusculares como Parkinson, acidentes vasculares, doença de paralisia de nervo craniano ou bulbar e esclerose lateral amiotrófica e outras como, dentição em má condição, úlceras orais são mais comuns na disfagia orofaríngea. Na disfagia esofágica são três tipos de doenças mais comuns: doenças da mucosa como tumores esofágicos e lesão cáustica (por exemplo, ingestão de desinfetante, esofagite medicamentosa), doenças mediastinais como infecções (por exemplo, tuberculose e histoplasmose), e ainda, doenças neuromusculares esclerodermia pós-cirúrgicas (MALAGELADA et al. 2004).

\subsection{DOENÇAS E PERDA DAS AÇÕES COGNITIVAS EM IDOSO}

$\mathrm{O}$ cérebro pode ser visto como uma grande central de comando extremamente complexa onde se iniciam todos os processos físicos. Cada ação iniciada no cérebro são sinais e estímulos cognitivos para falar, pensar, mover, e é claro alimentar-se (ACHILLES, 2004 tradução nossa).

Sendo assim, "o envelhecimento traz consigo uma serie de precauções entre as quais se destacam as queixas dos idosos em relação ao seu funcionamento cognitivo" (GOMEZ, 2013). A este propósito Schlindwein-zanini (2010: 221) reafirma que:

$\mathrm{O}$ ingresso na faixa etária considerada idosa traz muitas mudanças ao ser humano. No caso do cérebro, ocorrem modificações morfológicas[...] Nota se diminuição do número de neurônios e sinapses, além da existência de sintomas psicológicos e físicos como os lapsos de memória, menor velocidade de raciocínio, episódios passageiros de confusão, tremor, dificuldade de locomoção, insônia noturna com sonolência diurna e falta de equilíbrio.

A demência, por exemplo, como descreve Caldas (2011: 52),

Hoje é reconhecida como uma síndrome caracterizada por deterioração intelectual que ocorre em adultos e é tão severa que interfere no desempenho social da pessoa. Ocorrem alterações cognitivas que incluem distúrbios de memória, linguagem, percepção, práxis, habilidade de desempenhar o autocuidado, capacidade de solucionar problemas da vida cotidiana, pensamento abstrato e capacidade de fazer julgamentos.

Ainda sobre a demência são inúmeras suas causas mais frequentes, doença de Alzheimer, demência vascular, demência com corpos de Lewy e demência frontotemporal, o que a faz ter uma relação direta com idosos que venham a desenvolver disfagia (BARBOSA; CARAMELLI, 2002).

Com relação a todos os fatos já citados Monteiro (2009: 34) afirma que, "essa série de modificações anatômicas e funcionais que ocorrem com os idosos é relevante 
aos aspectos nutricionais dos mesmos. Entre elas, o olfato, o paladar e a visão influenciam negativamente a ingestão de alimentos". Contudo, é fato que o alimento desenvolve uma dupla ação quando interagido com o ser humano, além do fator nutricional já mencionado, ele atua como estimulador de sentidos como visão, olfato e paladar (CAVALCANTI, 1999).

Os seguintes autores Monteiro (2009), Gatto (2010), Schiffman (2007), Chiari, Bomfime Roque (2010), Suzuki (1996), Carvalho e Tavares (2012),Passos (2010), Colares et al. (2008),Jesus et al. (2011), Cárdenas e Silva (2007), Boccanera (2007), Alves e Dantas (2011), trazem em amplitude a coerente afirmação de que com o avançar da idade o ser humano oblitera disfunções dos cinco sentidos, estando relacionado a doenças demenciais ou não, sendo assim segundo Brasil (2007), 90\% das pessoas idosas sofrem de alguma acuidade referente ao cinco sentidos.

\begin{abstract}
No processo natural de envelhecimento, a visão, a partir dos 60 anos, passa a apresentar sinais de deterioração[...]. Ouvido, à medida que envelhece, vai perdendo a sua capacidade de funcionar; esses sinais já aparecem aos 50 anos[...]. O tato, também, é reduzido com o passar doa anos, implicando que no idoso esse quadro é um tanto complexo, visto que os demais órgãos, também se desgastam com o avanço da idade[...]. Quanto ao olfato e paladar, esses sentidos estão, extremamente, ligados à grande perda do interesse e motivação nessa idade; isto porque, com o envelhecimento, esses sentidos ficam bastante reduzidos (LIMA, 2007: 01-04).
\end{abstract}

A perda sobre a percepção sensorial dos alimentos é resultante de uma série de fatores em sua grande maioria relacionados com o nosso sistema nervoso central, sendo esse fato gerador de enfermidades tanto nutricionais como sociais ao paciente idoso. Em função destes resultados é necessária a aplicação de técnicas junto a alimentação do idoso, envolvendo cor nos alimentos, aroma e sabor, evitando assim a alimentação por sonda (MAGALHÃES, 2011).

Nesse sentido, pode-se ressaltar a importância da alimentação e de dietas adequada na fase idosa, sabendo que o avanço da idade gera consigo em grande parte das vezes doenças que afetam nossos sentidos de forma degenerativa (sem cura) como a demência relacionada, a doença de Alzheimer. Estando a demência (seja ela degenerativa ou não) presente em metade dos idosos que apresentam comprometimento na fase oral, ou seja, nos comandos cognitivos responsáveis pela alimentação causando problemas sérios como desidratação, desnutrição e pneumonia, além do risco de morte por asfixia. Portanto, é relevante o conhecimento da dinâmica alimentar do idoso que se apresenta em tal situação (CHIARI; BOMFIM; ROQUE, 2010). 
Frequentemente a acuidade seja ela visual ou gustativa manifesta-se no fato de a pessoa não comer porque é incapaz de reconhecer os alimentos; bem como não utilizar os utensílios porque não sabe o que fazer com eles, fator que se complica quando somados os casos de disfagia, Alzheimer e demência. A apraxia e a agnosia determinam que os doentes por vezes tenham que ser "mimados" para comer, misturar e brincar com os alimentos continuamente durante as refeições é algo frequente no cotidiano de um idoso com esses problemas (MELO, 2005).

Contudo, neste caso, depare-se com o desafio que não é apenas o de produzir alimentos e dietas que consigam contemplar todas as exigências de um paciente idoso, entendendo que independentemente da idade e da patologia em questão (demência, Alzheimer, Parkinson), o ato de comer ainda envolve uma seleção, uma escolha, ocasiões e rituais que estão diretamente ligados a vivência desse paciente, entender que não devemos suprir apenas o biológico ou nutricional (fome), e sim saciar o apetite psicológico desse idoso de forma a auxiliar em seu tratamento (CARDOSO et al., 2014).

\subsection{TIPOS DE DIETA PARA DISFAGIA}

Como já relatado nesse estudo a disfagia e suas doenças relacionadas afetam profundamente a qualidade de vida dos pacientes tanto no aspecto social quanto no fisiológico, sendo assim, o fornecimento de todos os nutrientes é um grande desafio quando se trata de dietas com consistência modificada, e a intervenção nutricional deve sempre levar em questão os graus (leve, moderada e grave), de disfagia do paciente (PIVI, SCHUULTZ E BERTOLUCCI, 2013). Para cada grau de disfagia existem orientações e restrições como exemplificado no quadro 3:

Quadro 3 - Graus de gravidade de disfagia

\section{Leve}

Moderada

Grave
O paciente apresenta dificuldade para engolir algumas consistências, em geral líquidos finos, pode haver episódios de engasgo. São orientadas as refeições frequentes e em porções menores. O paciente precisa de mais tempo para se alimentar.

O paciente apresenta restrição em duas ou mais consistências. Ocorre dificuldade em iniciar deglutição o que facilita o desvio do alimento para a abertura laríngea com posterior aspiração, com presença de tosse, engasgo, pigarro, e "voz molhada". Há necessidade de orientação quanto à postura adequada.

$>$ O uso de uma via alternativa para alimentação é indicado (dietas por sonda gastroenteral), tanto para complemento como para alimentação exclusiva. Pode ocorrer aspiração, inclusive de saliva, A via oral deve ser usada como via de conforto na consistência prescrita.

Fonte: Adaptado de PIVI, SCHUULTZ e BERTOLUCCI, 2013. 
Sendo assim, "prover deglutição para indivíduos disfágicos é um desafio, contudo esta pode ser facilitada se os alimentos tiverem a textura modificada e os líquidos forem espessados" (PAGNO, 2009: 7). Neste contexto Sousa et al. (2003) descreve que não pode se falar em disfagia sem ao menos mencionar a mudança nas texturas e viscosidades dos alimentos, a textura para o disfágico envolve seu sentido de tato e audição, e a identificação de suas características: firmeza, elasticidade, fraturabilidade $^{3}$, mastigabilidade ${ }^{4} /$ dureza, adesibilidade $^{5}$, coesão e viscosidade. Sobre a viscosidade Oliveira et al. (2008: 74) complementa que a "viscosidade ou resistência do líquido ao fluxo, ou seja, a densidade do líquido. Existem quatro tipos de viscosidade dos alimentos: ralo, néctar, mel e pudim”.

Ainda sobre as texturas dos alimentos, elas podem ser divididas entre líquidos: néctar, mel e pudim e sólidos: branda, pastosa e pastosa homogênea, sendo de suma importância a compreensão e a relação de ambas com o grau de disfagia para a construção de um cardápio adequado (PIVI, SCHUULTZ E BERTOLUCCI, 2013). Tais mudanças na dieta podem ser observadas de forma mais específica no quadro 4 :

Quadro 4 - Tipos de consistência adotadas em disfagia

\begin{tabular}{|c|c|}
\hline \multicolumn{2}{|r|}{ SÓLIDOS } \\
\hline Branda & $\begin{array}{l}\text { Branda: consistência dos alimentos naturalmente alterada pela cocção. Os } \\
\text { alimentos naturalmente macios podem ser consumidos. Devem ser evitados } \\
\text { alimentos que fornecem resíduos não digeríveis como frituras, a maioria dos } \\
\text { vegetais, frutas cruas e cereais integrais. Evitar condimentos em excesso } \\
\text { para não estimular a salivação. }\end{array}$ \\
\hline $\begin{array}{c}\text { Pastosa } \\
\text { Heterogênea }\end{array}$ & $\begin{array}{l}\text { Consistência dos alimentos atenuada pela cocção a ponto de ser possível } \\
\text { amassa-los com um garfo, podendo ser umedecidos com caldos e molhos. } \\
\text { Carnes somente cozidas e desfiadas, frutas e vegetais macios e bem cozidos. }\end{array}$ \\
\hline $\begin{array}{l}\text { Pastosa } \\
\text { Homogênea }\end{array}$ & $\begin{array}{l}\text { Consistência dos alimentos é de purê, após acentuado cozimento. Para isso } \\
\text { após a cocção os alimentos devem ser batidos e peneirados e quando } \\
\text { necessário, espessados. Todos os alimentos devem ser servidos em uma } \\
\text { consistência homogênea. }\end{array}$ \\
\hline \multicolumn{2}{|r|}{ LÍQUIDOS } \\
\hline Néctar & $\begin{array}{l}\text { Líquido ligeiramente espessado. Consistência em que líquido escorre da } \\
\text { colher formando um fio. }\end{array}$ \\
\hline Mel & $\begin{array}{l}\text { Líquido espessado, com textura encorpada. Ainda pode ser consumido ou } \\
\text { tomado diretamente de um copo }\end{array}$ \\
\hline Pudim & $\begin{array}{l}\text { Líquido espessado até adquirir consistência que pode ser ingerida apenas } \\
\text { com auxílio de uma colher. }\end{array}$ \\
\hline
\end{tabular}

Fonte: Adaptado de PIVI, SCHUULTZ e BERTOLUCCI, 2013.

\footnotetext{
${ }^{3}$ É a força pela qual uma amostra salta dos dentes ao esmigalhar ou quebrar em pedaços (ARAUJO, 2009).

${ }^{4}$ É julgada sensorialmente como a força necessária para penetrar uma substância com o dente molar. Quanto maior a força necessária para penetrar o alimento, maior é sua dureza (ARAUJO, 2009).

${ }^{5}$ É julgada pela força necessária para remover um material que adere à boca. Quanto mais difícil for para remover um material de seus dentes, palato, etc, maior adesibilidade do material. (ARAUJO, 2009).
} 
Toda a conduta de produção dos alimentos deve respeitar essas fases, sendo importante reforçar que os líquidos ralos dificultam a deglutição de pacientes que apresentam o controle oral reduzido e ainda aumentam o risco de aspiração do alimento. Podendo ocasionar a morte (SOUZA et al., 2003).

Contudo, é de suma importância ressaltar que algumas texturas que seriam adequadas a pacientes disfágicos, só são possíveis graças a agentes espessantes, a padronização das receitas, e ao treinamento do profissional responsável (LAGES; RIBEIRO; SOARES, 2013).

Em relação a tal aspecto Pivi, Schuultz e Bertolucci (2013: 202), levantam outro cuidado a ser tomado que é a "relação às características organolépticas (cor, sabor e aroma) itens que devem ser considerados ao máximo para garantir a aceitação da dieta". Uma dieta pastosa pode ocasionar a diminuição do prazer associado à comida e do bemestar de comer socialmente (ANTUNES et al., 2012). Diante de tal afirmações "Ao elaborar a dieta para disfagia, é preciso levar em consideração os princípios e as regras das técnicas dietéticas. As refeições devem ser planejadas de forma criativa. Visualmente, precisam ser atrativas. Além disso, é importante que tenham sabor e aroma" (SOUZA et al., 2003: 39).

\subsection{O ALIMENTO E OS CINCO SENTIDOS NA GASTRONOMIA HOSPITALAR}

“O alimentar-se é um ato vital, sem o qual não há vida possível, mas, ao se alimentar, o homem cria práticas e atribui significados àquilo que está incorporando a si mesmo, o que vai além da utilização dos alimentos pelo organismo" (MACIEL, 200: 145). "A sensação fisiológica pelo qual o corpo percebe que necessita de alimento vai além das necessidades biológicas, alimentar-se é uma expressão dos variáveis desejos humanos e cuja satisfação não obedece apenas ao curto trajeto que vai do prato à boca" (CARNEIRO, 2003: 01).

Portanto, pode-se entender que a alimentação resulta em múltiplas sensações e que a gastronomia é o meio de expressão que comunica sentimentos e emoções, ou seja, a percepção do alimento envolve a participação dos cinco sentidos, sendo assim, ao ofertar um alimento seja ele a quem for é importante atender as expectativas de todos os sentidos (ARAUJO et al., 2009).

No entanto, mesmo sendo a alimentação um dos primeiros recursos terapêuticos com que contou a medicina em seus primórdios (SOUZA; NAKASATO, 2011), o 
alimento no âmbito hospitalar até pouco tempo "era tradicionalmente visto sob a ótica do aspecto nutricional e higiênico-sanitário, chegando-se mesmo a ignorar o lado humano e sociológico da alimentação" (CARDOSO, 2014: 2).

Face a isto, comer em uma instituição hospitalar nessas condições se torna um fardo como reforça Corbeau (2005: 235)

Comer pode também significar a inflexão, o aprisionamento. Nesse caso, consumir o alimento não conduz mais à curiosidade intelectual, à acuidade e à mobilização dos sentidos susceptíveis de decodificar, reconhecer, apreciar, memorizar a emoção gustativa e os prazeres percebidos.

Neste contexto, deve-se entender que os sentidos cognitivos do ser humano são importantes em qualquer dieta (SOUZA; NAKASATO, 2011), as sensações percebidas pelos sentidos, não só definem a qualidade sensorial dos alimentos, como o instigam a refletir sobre ele (ARAUJO et al., 2009).

Corroborando com a ideia de que os cinco sentidos definem a qualidade dos alimentos, os seguintes autores: Brasil (2007), Alves e Dantas (2011), Jesus et al (2011), Monteiro (2009), Gatto (2010), Campos (2008), Araujo (2009), afirmam que uma dieta deve ser composta por elementos como cor, temperatura, aroma, sabor e textura, contribuindo para aumentar a ingestão alimentar e possibilitando uma integração com os sentidos visão, olfato, paladar, audição e tato, sendo o conjunto de fatores primordiais para uma análise das percepções dos cinco sentidos de pacientes que, na maioria das vezes, têm percepções negativas quanto à alimentação hospitalar.

Com a visão é possível definir as características físicas dos alimentos, o paladar é diretamente sugestionado pela cor. "É tamanha a expressividade das cores que ela se torna um transmissor de ideias, tão poderoso que ultrapassa fronteiras espaciais e temporais. Não tem barreiras nacionais e sua mensagem pode ser compreendida até por analfabetos" (FREITAS, 2007: 1).

Geralmente, a cor que mais atrai é o laranja seguido pelo vermelho. A cor tem atuação sobre a mente e a sensibilidade, estando ligadas diretamente às funções ópticas, fisiológicas e neurológicas. A cor tem influência direta na expectativa de sabor dos alimentos (FREITAS, 2007).

Diferente da visão que reage a estímulos físicos, o olfato e o paladar reagem a estímulos químicos (SANTAELLA, 2005), mesmo assim, olfato também como a visão contribui para uma pré-degustação do prato, sendo que, muitas vezes só conseguimos saborear algo se a percepção dos aromas está intacta, mesmo porque sentir o odor do 
alimento estimula mais o apetite do que a visão. Isso porque o que chamamos de "gosto" do alimento na verdade é o processo da comida sendo mastigada e liberando odores que se espalham pelo nariz (CANABRAVA et al., 2006, ARAUJO et al., 2009). Corroborando com a ideia Savarin (1995) refere que não há degustação completa sem a participação do olfato, sendo que a boca serve para degustação dos corpos táteis e o nariz para degustação dos gases.

A audição é a capacidade de perceber sons, esses sons permitem a audição provocar a percepção da textura de seu alimento, da mesma forma que o olfato interage com o paladar a audição interage com o tato que interagindo na percepção de textura, dos dedos. O tato ainda ajuda na percepção de temperatura (CAMPOS, 2008).

Contudo é preciso compreender a importância do paladar, afinal é através dele que selecionamos os sabores ácido, doce, amargo e salgado (MOUSSALLE et al., 1997), e é o sentido que inicia nossa digestão, no que seria um processo pré-digestivo (ARAUJO et al., 2009). Porém, o paladar vai além da simples teoria biológica, segundo Cascudo (2004), possui um amplo significado cultural é um elemento poderoso e permanente na delimitação das preferências alimentares, modificar o paladar de uma pessoa é algo além dos fundamentos e argumentos médicos de que determinados alimentos oferecem um maior valor nutritivo, a modificação desse paladar depende apenas do fator que o formou o tempo. "É inútil pensar que o alimento contenha apenas os elementos indispensáveis a nutrição. Contém substâncias imponderáveis e decisivas para o espírito, alegria, disposição criadora e bom humor" (CASCUDO, 2004: 348).

Diante dessas afirmações é lúcido o pensamento de Lévi-Strauss (2004) em que o alimento não serve somente para comer, serve para pensar. Neste caso depare-se com o grande desafio da gastronomia no âmbito hospitalar como descreve Corbeau (2005), o de compreender que no meio hospitalar o comer não seja nada transparente, que as perspectivas simbólicas do alimento sejam difíceis de se representar já que muitos dos consumidores são incapazes de identificar o alimento, dessa forma, alguns tenham às vezes tendência a querer reduzir o alimento a um simples estatuto de nutriente.

\section{METODOLOGIA}

A pesquisa foi realizada no mês de abril a junho de 2015 com um grupo de idosos (hóspedes) e funcionários de uma Instituição de Longa Permanência para Idosos (ILPI), de Florianópolis, sendo esta uma casa geriátrica que hospeda atualmente 29 
idosos, com patologias decorrentes do processo de envelhecimento como Diabetes Mellitus, Demência, doença de Alzheimer, Osteoporose, Hipertensão arterial, dentre outras.

Para a coleta de dados foi utilizada a técnica de entrevista semiestruturada, aquela que permite que o entrevistado traga à tona toda sua subjetividade e riqueza de suas experiências onde as condições para tal são a priori aceitas (SANTOS; CANDELORO, 2006), em situação individual, aplicada em 13 indivíduos funcionários da ILPI. Antes do início da entrevista propriamente dita solicitamos aos participantes que assinassem o termo de consentimento livre e esclarecido aprovado (mesmo sabendo que a faculdade não possui um Comitê de Ética em Pesquisa), em que se documentava sua disposição de participar voluntariamente do estudo. Seguiu-se um roteiro com algumas questões norteadoras, que funcionaram como um guia e facilitaram a abertura, a ampliação e o aprofundamento da comunicação, sendo que essas sessões foram gravadas em áudio.

O estudo caracteriza-se como qualitativo, observacional e descritivo abordando o incentivo ao uso de alimentos coloridos com odor atrativo que despertem percepções nos cinco sentidos durante a alimentação de idosos com disfagia na ILPIs, referente ao estudo.

Para que um desenvolvimento de conhecimento possa ser expresso nesse trabalho acadêmico, e por sua vez considerado científico, é necessário que haja uma organização das operações mentais e técnicas a fim de estabelecer uma ordem ao conhecimento que deva possibilitar sua verificação (GIL, 2008).

Para Fachin (2006: 15), conhecimento científico pode caracterizar-se:

[...] pela presença de acolhimento metódico e sistemático dos fatos da realidade sensível. Por meio da classificação, da comparação, da aplicação dos métodos, da análise e síntese, o pesquisador extrai do contexto social, ou do universo, princípios e leis que estruturam um conhecimento rigorosamente válido e universal.

Um dos métodos utilizados nesse trabalho foi o método indutivo que segundo Gil (2008: 10) "o método indutivo procede inversamente ao dedutivo: parte do particular e coloca a generalização como um produto posterior do trabalho de coleta de dados particulares". "As preposições do método indutivo são concretas e descrevem como são os fenômenos, suas causas e efeitos reais" (NETO, 2005: 26).

Outro método utilizado pelo para o desenvolvimento e análise dessa pesquisa foi o observacional que de acordo com Gil (2008: 5) "O observacional difere do 
experimental em apenas um aspecto: nos experimentos o cientista toma providências para que alguma coisa ocorra, a fim de observar o que se segue, ao passo que no estudo por observação apenas observa algo que acontece ou já aconteceu”"

Sobre a análise qualitativa Godoy (1995: 4), explana que “a análise qualitativa apesar de ter sido regularmente utilizada pelos antropólogos e sociólogos, só nos últimos trinta anos começou a ganhar um espaço reconhecido em outras áreas, como a psicologia, a educação e a administração de empresas". Corroborando com a ideia Sousa et al. (2007), afirma que "as pesquisas qualitativas possuem características multimetodológicas, utilizando um número variado de métodos e instrumentos de coleta de dado". Ainda fazendo referência à pesquisa identificada como qualitativa, podemos citar que é um método de "contato direto do pesquisador com a situação estudada, procurando compreender os fenômenos segundo a perspectiva dos sujeitos, ou seja, dos participantes da situação em estudo (GODOY, 1995: 06).

Para outros procedimentos técnicos da pesquisa serão utilizados dados de pesquisas obtidos por fontes bibliográficas e observação participante que segundo Sousa et al. (2007) "a observação torna-se uma técnica científica a partir do momento em que passa por sistematização, planejamento e controle da objetividade”. Em relação à pesquisa bibliográfica Oliveira (2008: 119) afirma que "O levantamento bibliográfico é mais amplo do que a pesquisa documental. A pesquisa bibliográfica tem por finalidade conhecer as diferentes formas de contribuição cientifica que se realizaram sobre determinado assunto ou fenômeno". Por analogia “a pesquisa bibliográfica é desenvolvida com base em material já elaborado, constituído principalmente de livros e artigos científicos" (GIL, 2008: 50).

Outros dados foram coletados mediante análise do prontuário e observação de uma refeição (almoço), em tempo real de cada idoso, buscando visualizar mudanças nas ações cognitivas e atitudes referente a alimentação. Ambos os dados obtidos estão representados nesse estudo de forma descritiva. É importante ressaltar que os dados coletados nos prontuários foram doenças, idade, e Grau de disfagia como observado no quadro 5 a seguir.

Quadro 5 - Dados dos hospedes com disfagia

\begin{tabular}{|c|c|c|c|}
\hline PACIENTES & DOENÇAS & IDADE & $\begin{array}{c}\text { GRAU DE } \\
\text { DISFAGIA }\end{array}$ \\
\hline Paciente 1 & Sequela de AVC, Depressão. & 76 anos & Grave \\
\hline Paciente 2 & Demência, Câncer do Colo do útero, Diabetes & 94 anos & Moderada \\
\hline Paciente 3 & Demência & 86 anos & Grave \\
\hline Paciente 4 & Demência senil & 96 anos & Grave \\
\hline
\end{tabular}




\begin{tabular}{|c|c|c|c|}
\hline Paciente 5 & Câncer esôfago, Hipertensão arterial sistêmica, Diabetes. & 87 anos & Grave \\
\hline Paciente 6 & Alzheimer, & 82 anos & Moderada \\
\hline Paciente 7 & Alzheimer, Hipertensão arterial sistêmica & 94 anos & Moderada \\
\hline Paciente 8 & Alzheimer, Demência & 90 anos & Moderada \\
\hline Paciente 9 & Demência & 100 anos & Grave \\
\hline Paciente 10 & Demência & 99 anos & Grave \\
\hline
\end{tabular}

Fonte: Elaborado pelos autores 2019.

A utilização dos métodos supracitados colaborou para a obtenção de informações fundamentais para o desenvolvimento do trabalho, facilitando a compreensão de cada componente utilizando na estruturação do projeto.

\section{ANÁLISE DOS DADOS}

Os funcionários foram questionados a respeito do principal objetivo desse estudo, a análise das percepções dos cinco sentidos dos pacientes com disfagia, nas entrevistas foram realizadas perguntas sobre a mudança de cardápio e a intervenção de cores na alimentação da ILPIs e se os mesmos reconhecem e percebem a ação dos cinco sentidos nos hospedes (pacientes com disfagia) durante a alimentação, sua participação nas atividades alimentares diárias desse grupo fez com que obtivessem experiência para tal relato. “Após a leitura das entrevistas, organizadas em torno de eixos temáticos sugeridos pela leitura e análise das entrevistas, buscou-se definir as categorias empíricas que emergiram dos discursos dos sujeitos entrevistados" (SÁ; RABINOVICH, 2006). Cabe lembrar que foi realizada uma observação dos idosos na hora das refeições buscando identificar aspectos recorrentes, convergentes ou divergentes nos relatos dos funcionários, bem como toda a implementação do novo cardápio pelo autor desse estudo.

Em face do panorama apresentado até o momento no referido estudo, é importante destacar o método utilizado para a preparação do antigo cardápio para os hóspedes disfágicos. A "papa pastosa", como era chama a comida da figura 2. Consistia-se em um prato único que apresentava um padrão nutricional aceitável, variava do amarelo escuro ao cinza devido ao modo de preparo que se resumia a cozinhar tudo em uma panela (carnes, legumes, tubérculos etc.), bater em um liquidificador, peneirar e espessar quando necessário com amido de milho. Neste contexto, coube ao autor desse estudo a compreensão de que a gastronomia é uma importante ferramenta na implantação de um serviço humanizado dentro de um hospital (NAKASATO, 2014), ou seja, a refeição apresentada na figura 2 não configura com a pesquisa apresentada até o momento nesse estudo. 
Figura 2 - Comida pastosa anterior a pesquisa

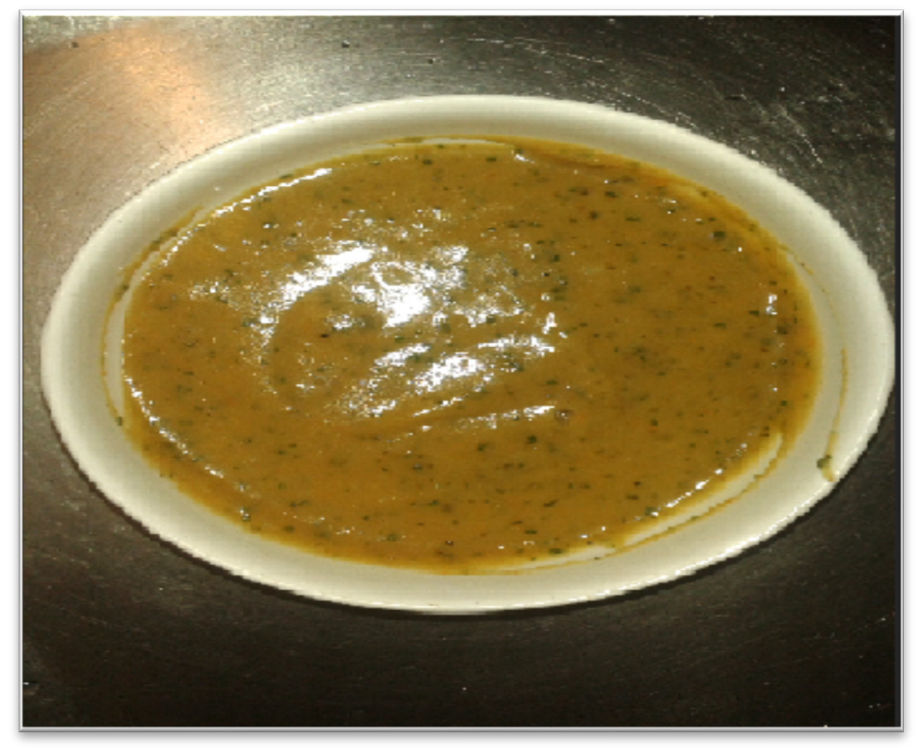

Fonte: Elaborado pelos autores 2019.

Corroborando com a ideia de intervenção gastronômica temos como exemplo o filme A Festa de Babette (1987), onde se destaca a transformação realizada por Babette (ex-chef "Café Anglais" em Paris) em um prato de sopa, que era servido por duas irmãs em uma pequena vila da Dinamarca, onde antes existia ausência de sabor e prazer passou a existir (embora seja uma preparação singela) sabor e alegria ao comer, por parte dos comensais que recebiam a sopa. A sopa que antes era somente consumida para prover as necessidades nutricionais, após a intervenção de Babette passou a ser também um momento de prazer aos sentidos.

Portanto, é preciso entender a gastronomia como: "a preferência apaixonada, racional e habitual de todos os objetos que agradam ao paladar" (SAVARIN, 1995: 107). Em vista disso criou-se um novo método para a produção da comida destinada aos hóspedes com disfagia, essa nova maneira de preparo consiste em cozinhar e bater os ingredientes separados, de forma a conseguir obter três ou mais preparações diferentes que pudessem, apesar da mesma textura serem destacadas pela cor, aroma e sabor diferenciados. O método de peneirar continuava o mesmo, embora o espessamento agora na maioria das vezes seja feito com o amido natural do próprio alimento, esse novo prato recebeu o nome de "trio pastoso", em relação a quantidade de cores que aparecem no prato, como pode ser observado no quadro 6. Sobretudo, é importante aliar a uma dieta hospitalar, não somente o conceito das prescrições nutricionais, mas também os conceitos relacionados a gastronomia, como as dimensões simbólicas e 
sensoriais da alimentação, bem como as técnicas utilizadas para sua preparação (NAKASATO, 2014).

Quadro 6 - Novo cardápio pastoso

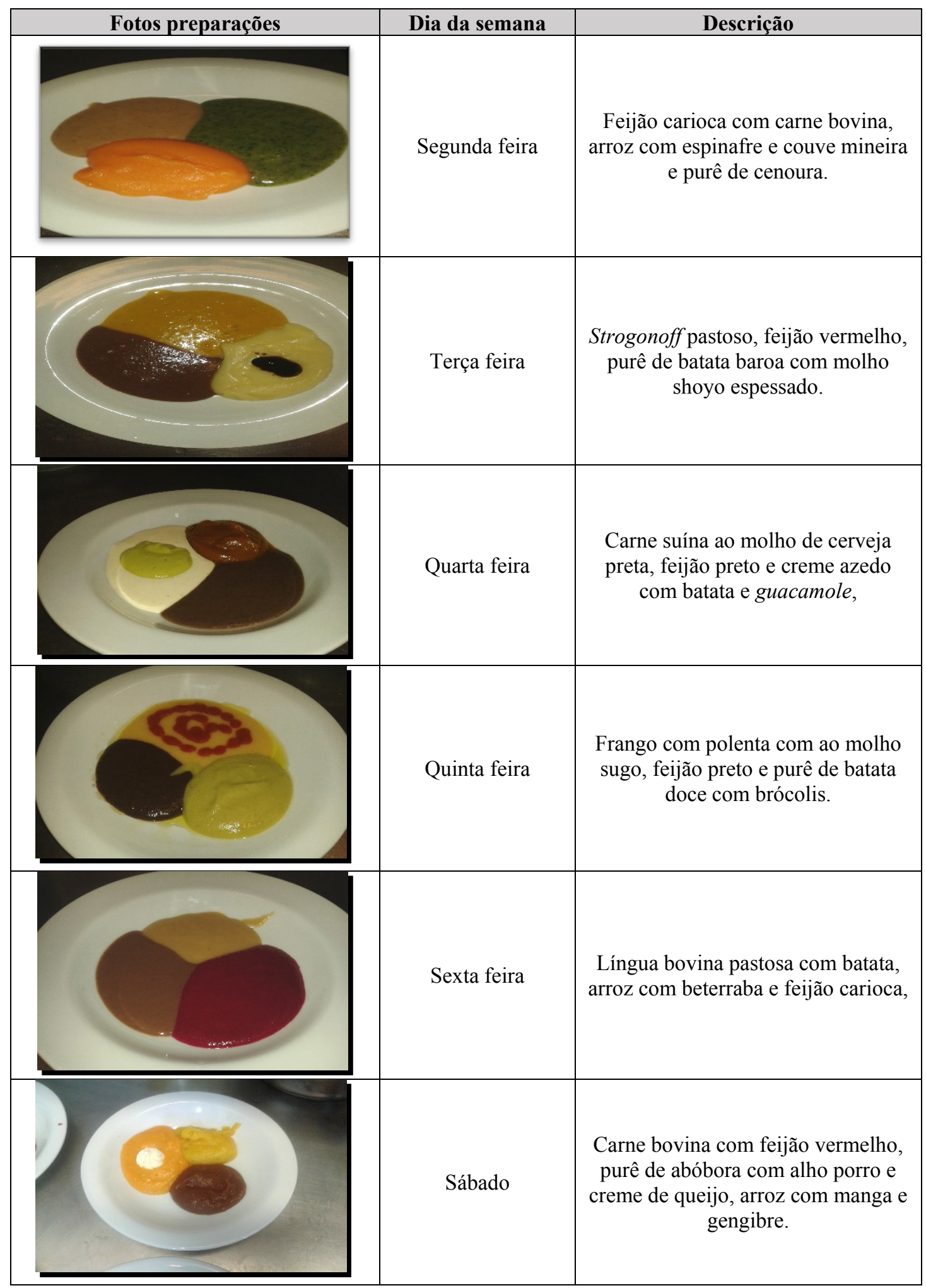




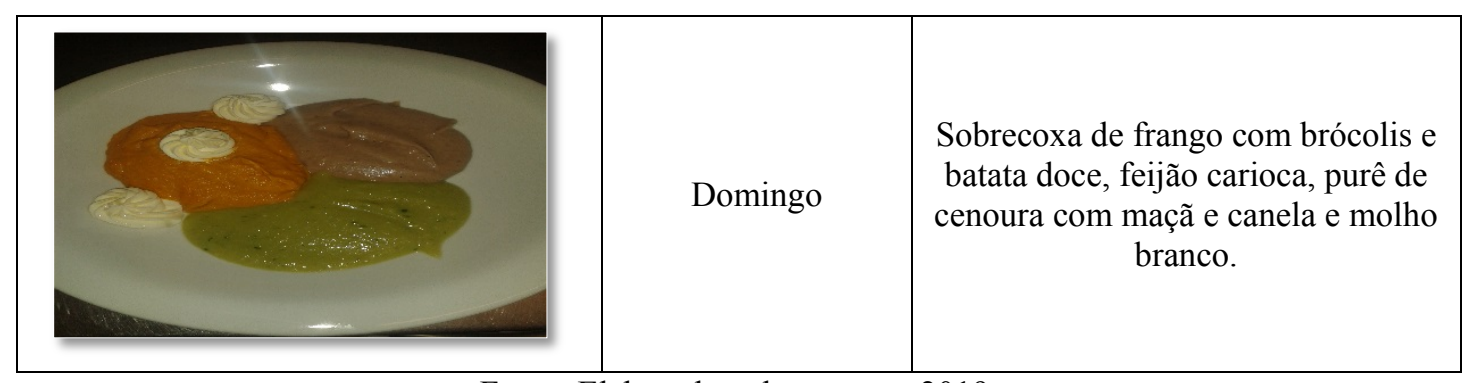

Fonte: Elaborado pelos autores 2019.

A priori nessa pesquisa, em relação ao gênero, foi observado que a maior parte dos funcionários entrevistados eram compostas por mulheres 97\%, essa regra acontece em quase todas as ILPIs que de acordo com Cattani e Girardon-perlini (2004) é "determinada pelo expressivo traço cultural existente hoje em nossa sociedade, na qual a mulher é que detém o papel de cuidadora".

Referente ao estudo também se mostrou relevante saber o nível de conhecimento científico dos funcionários entrevistados sobre disfagia e seus riscos para a saúde dos idosos, em relatos como:

Disfagia dificuldade de deglutir, o paciente que tenta comer e não consegue tem dificuldade (ENTREVISTADO (a) 1).

Incapacidade do ser humano de deglutir. Basicamente isso o conceito que eu conheço (ENTREVISTADO (a) 3).

[...] é dificuldade de engolir, pode ficar acúmulo na garganta e a broncoaspiração (ENTREVISTADO (a) 10).

De maneira geral foram respostas sucintas, mostrando a importância de se realizar um treinamento continuo dos funcionários perante as atividades realizadas na instituição, para que haja um conhecimento mais aprofundado referente ao tema em que trabalham, e assim poderem ter atitudes ativas no seu desempenho laboral, como afirma Chiavenato (1998: 493), "treinamento é o ato de preparar as pessoas para o ambiente de trabalho tanto dentro como fora dela, em que o indivíduo é profundamente influenciado no meio em que vive, trabalha e desenvolve suas habilidades e conhecimentos em várias tarefas realizadas".

Todavia, quando abordados sobre o cotidiano, referente ao objetivo desse estudo que é análise das percepções dos cinco sentidos em pacientes com disfagia, observou-se que a excelência no exercício da prática só se consegue participando dela e no caso dos funcionários da ILPIs, a pesquisa funcionou com excelência, devido ao fato de veem os idosos como seres totais, que possuem família, cultura, têm passado e futuro, crenças e 
valores que influenciam nas experiências de saúde e doença deles (SILVA; BATOCA, 2003).

Portando quando perguntados sobre as referências visuais dos idosos quanto a antiga alimentação (figura 2), obteve-se o seguinte relato:

Sendo sincera: horrível, é que o paciente julga o prato pela cor se o prato táescuro a minha paciente não vai se interessar, mesmo que o sabor esteja bom, se o prato não tiver de acordo com os olhos dela ela não vai querer, antigamente não tinha isso era tudo misturado de uma cor só, não tinha alegria naquele prato tinha tristeza (ENTREVISTADO(a) 01);

Anteriormente era feito basicamente uma mistura de vários alimentos, tentavam garantir as questões nutricionais, mas com baixa preocupação com o aspecto visual né? Então comparado com hoje que são feitas 3 cores com certeza se tornou mais atrativo.(ENTREVISTADO(a) 03);

Horrível, eles achavam ruim, não dava vontade de comer (ENTREVISTADO(a), 04).

O adjetivo "horrível" usado nas descrições refere-se as preparações semelhantes a figura 2, que eram servidas anteriormente no estabelecimento. É perceptível no relato que apesar dos órgãos dos sentidos: visão, audição, tato, paladar, olfato, o que ocorre maior perda funcional é a visão (RODRIGUES; DIOGO, 2004), mesmo assim, no caso do relato anterior que se refere a paciente 08 com patologias como Alzheimer, demência existe uma diferenciação uma preferência e um reconhecimento do alimento colorido. Outro relato do cotidiano que afirma essa observação é o da Entrevistado(a) 07.

A comida anterior era muito importante na questão nutricional para alimentar eles naquele momento, mais era só de uma cor, ai hoje você vê que é diferente. Agora você vê que a cenoura tá ali no prato, o feijão tudo separado, nós percebemos que fica melhor pra eles o paciente vê um prato colorido na frente dele ele não se sente tão lesado em estar comendo um mingau, uma papa sem brilho, estou comendo vários alimentos (ENTREVISTADO (a) 07).

A perda do paladar e do olfato pode levar o idoso a não distinguir o sabor do alimento, por isso é tão importante estimular seus sentidos através de um variado cardápio com diferentes preparações, se demonstrou importante com o decorrer da pesquisa usar tonalidades de cores que favoreçam a boa reflexão de luz, despertando assim a curiosidade e anulando a falta de interesse sofrida com a alimentação anterior (BRASIL, 2007).

Com o novo cardápio houve não só uma melhoria visual na alimentação, como uma mudança radical na maneira dos hóspedes receberem a comida e de suas cuidadoras a ofertarem. É sentido no relato anterior a percepção da importância do alimento não apenas como fator nutricional, e sim como valores agregados a refeição, 
comer agora não é apenas uma necessidade vital, é um momento repleto de significados como afirma Maciel (2005: 50)

Indo mais além de sua dimensão biológica, a alimentação humana como um ato social e cultural faz com que sejam produzidos diversos sistemas alimentares. $\mathrm{Na}$ constituição desses sistemas, intervêm fatores de ordem ecológica, histórica, cultural, social e econômica que implicam representações e imaginários sociais envolvendo escolhas e classificações. Assim, estando a alimentação humana impregnada pela cultura, é possível pensar os sistemas alimentares como sistemas simbólicos em que códigos sociais estão presentes atuando no estabelecimento de relações dos homens entre si e com a natureza.

Todavia, como seria possível desprezar anos de vivência cultural dos hóspedes em fator de uma patologia, bater tudo e misturar em uma única preparação (figura 2), seria ignorar escolhas e classificações que os idosos tiveram a vida inteira. Esse discurso está hoje presente nos funcionários da clínica:

Eu acho que a vantagem dessa alimentação é levar realmente em conta que se alimentar é muito mais do que colocar o alimento na boca e engolir, existe envolvido ali um recordatário alimentar, um desejo por um sabor ou por outro (ENTREVISTADO(a) 06).

[...] a vantagem visual e também a vantagem de sabor, por que o comensal, o nosso hospede, consegue perceber, qual é o alimento que está sendo dado para ele, não é mais uma mistura, consegue sentir o gosto do feijão, do arroz, sabe que tá comendo uma carne e não mais um sopão misturado (ENTREVISTADO(a) 03).

$\mathrm{O}$ ato de comer, portanto, independe da idade a sequência de comer nunca será apenas um vetor mecânico, antes, durante e depois tanto a identidade do alimento quanto a identidade do consumidor (idoso), permanecem presentes em interação (CORBEAU, 2005).

Quando tem algo que eles comem bastante e rápido dá pra notar que era algo que eles gostavam de comer antes e apesar da textura não ser a mesma o sabor faz ele recordarem a polenta com molho de galinha pra hóspede 01 deu pra ver isso (ENTREVISTADO(a) 13).

Como Corbeau (2005), afirma não é apenas consumidor que possui uma identidade o alimento possui suas características particulares, seus aromas, cores, texturas e sabores, o fato de unificar tudo isso em uma única mistura não contribui para a estimulação alimentar dos idoso em questão.

É importante saber o que tem, porque existe outra coisa, que é o que a gente chama de recordatário alimentar, se não tem valor a história da nossa vida se a nossa história não tem algum valor do que vale chegar aos 80 e aos 90 faz parte da minha história meu recordatário alimentar, e quando isso é levado em conta eu sou levado em conta, quanto ao sujeito que tem uma história (ENTREVISTADO(a), 06)

É possível fazer um resgate histórico, pelo fato da cor, e agente poder falar o que aquela cor representa qual o alimento ela éum feijão um brócolis que nem hoje faleipara hóspede 08, que era carne, pela cor ela recordou e o gosto, ela recordou e comeu falando da carne, ENTREVISTADO(a), 12). 
Levando esses relatos em consideração a nova alimentação implantada no ILPIs referente a esse estudo, trouxe uma nova ação no momento alimentar para os hóspedes com disfagia e na percepção dos seus sentidos: O poder de escolha dos alimentos consumidos.

Hoje eles escolhem o que querem comer, existem recusas ne. Então a gente consegue perceber quando ele não gostou do aspecto do prato que foi ofertado que não gostou da cor [...]. Mais fácil saber do que não gosta do que gosta (ENTREVISTADO(a), 03)

[...] eles têm poder de escolha, acho que o primeiro contato deles é o visual já a cor vai influenciar na escolha deles, informação verbal também é importante para identificação do prato (ENTREVISTADO(a), 04),

Corroborando com a mesma ideia de opção de escolha outros relatos são importantes para afirmar essa observação.

Eles têm opinião própria, nem tudo que está no prato eles comem, tipo a hóspede 01 e o hóspede 07 são pacientes que perguntam, procuram (ENTREVISTADO(a) 05).

Agora já vem separado, pelo fato de poder mostrar pro paciente, se ele não quer mais tentamos outra cor, antes era tudo misturado, ele dizia que não queria mais e não tinha como oferecer outra coisa (ENTREVISTADO(a) 12).

"Comumente pacientes com quadros demenciais apresentam perda de peso" (PIVI, SCHUULTZ E BERTOLUCCI, 2013), o fato de não ter opções de escolha e a recusa alimentar só agravam esse fato. Para uma boa alimentação é necessário que o alimento seja aceito pelo hóspede, o fator de escolha só é possível quando o alimento se apresenta de forma atrativa e variada, e a isso se deve a intervenção gastronômica na alimentação hospitalar (ANTUNES et al., 2012).

Contudo, ainda existem algumas situações onde o fator de escolha está impedido pela questão motora ou demência avançada, situação essa que fica clara no relato seguinte:

Porque assim quem come sozinho até tenta escolher, mais quem precisa de nós para se alimentar é o que a gente pega primeiro (ENTREVISTADO(a) 10).

Eles são diferentes um do outro, depende muito do paciente, eles pedem coisas diferente independendo do tempo que eles estão comendo a comida pastosa, como a hóspede 01 ela é lucida, e ainda pede comida normal todo dia, ela tem muito poder de escolha no prato embora ela não consiga se alimentar sozinha. Talvez ela comece melhor se ela se alimentasse sozinha mesmo sendo pastoso. ENTREVISTADO(a) 12).

Nesse contexto, é importante compreender o papel do(a) cuidador(a) como um sentido ampliado do idoso ou até mesmo um aguçador dos sentidos, já que cabe a ele demonstrar os alimentos presentes no prato (feijão, arroz, etc.), e enfatizar a coloração 
do alimento bem como cheiro, e o cuidado de ofertar um a um o alimento, pois o idoso já não consegue expressar verbalmente o que está querendo ou sentindo. É preciso desenvolver a habilidade de se comunicar com ele utilizando outros códigos (CALDAS, 2011). Todavia, essa proximidade do cuidar e zelar pelo paciente e a importância da ajuda no reconhecimento do alimento é perceptível nos relatos.

Os que comem sozinho observam melhor, até cortam a carne pastosa, sabem que estão comendo a carne, legume e arroz. É muito importante mostrar o prato porque eles tão sentados na mesa e estão observando né, eles não são muito de se comunicar, mais com os olhos eles reconhecem quando falamos olha a cenourinha. Eles não falam para você, mas com certeza eles olhando pro prato eles reconhecem o que eles estão comendo, devido o prato colorido (ENTREVISTADO(a) 07).

O papel da cuidadora é importante é ela que tem que estimular. O auxílio geral é importante (ENTREVISTADO(a) 08).

É imperativo abordar que as escolhas alimentares são vinculadas muito cedo, desde a infância, pelas sensações táteis, gustativas e olfativas (CANESQUI; GARCIA, 2005), ou seja, o novo cardápio não favoreceu apenas o visual é notado nos relatos e no processo de observação uma atividade dos cinco sentidos (olfato, paladar, tato, audição e visão) apesar das patologias e da idade em questão.

Esse prato trabalha com os sentidos a gente tira isso pelo hóspede 07, eu mostrei o prato ele achou que o escuro era chocolate, quando ele comeu ele cheiro e viu que era feijão" (ENTREVISTADO(a), 08 grifo nosso).

A hóspede 08 se ela vê um prato colorido, com vermelho, amarelo, verde ou até o branco, ela vai olhar e pela minha experiência em observar, ela experimenta uma colher de cada vez, aquela cor que ela gostar mais ela vai comer primeiro [...] mesmo perdendo alguns sentidos, outros ainda funcionam nela, ela voltou a ser criança na cabeça dela ela tem seis anos de idade, se que como na casa dela ela sempre comeu do bom e do melhor, ela não perdeu isso (ENTREVISTADO(a)01 grifo nosso).

[...] aguça, de todas as formas, até porque a hóspede01 e o 07 eles perguntam o que estão comendo, a gente fala eles observam pelas cores pelo gosto o cheiro. (ENTREVISTADO(a)05 grifo nosso).

O cheiro da comida tá mais cheirosa pra eles está sendo bom. O hospede 07 nem reclama muito, reclama mais é do café o café ele quer igual a dos outros sem espessantes ele não gosta dos espessamentos de líquidos, agora na comida não (ENTREVISTADO(a) 09 grifo nosso)

É importante perceber que o "cheiro" referido assim ao sentido do olfato, anteriormente ao novo cardápio não era percebido nos hóspedes. Segundo Barretos (2011: 09) "O sentido do olfato gera o surgimento de padrões mentais esquecidos, estimula conexões entre referências e desperta experiências retiradas e remotas que de alguma forma deixaram impressões do passado", sendo fundamental para o resgate histórico alimentar do hóspede. 
Contudo, pode ser observado que sentidos como audição e tato, tiveram grande ausência nas observações e entrevistas, isso se deve a textura do alimento pastoso, já que é a textura que ativa os receptores táteis e aditivos do nosso corpo (ARAUJO, 2009). A tabela 1 demonstra o número de vezes que cada sentido foi percebido pelos entrevistados, sendo em todas as vezes que se referiam ao tato, estavam se referindo a textura e quando se referiam a audição faziam uma ligação com o ruído ambiente e não o ruído do alimento.

Tabela 1 - Citações sobre os cinco sentidos durante as entrevistas

\begin{tabular}{|c|ccccc} 
& Olfato & Paladar & Audição & Tato & Visão \\
\hline Entrevistado 01 & 0 & 04 & 0 & 01 & 02 \\
\hline Entrevistado 02 & 0 & 0 & 01 & 0 & 03 \\
Entrevistado 03 & 02 & 03 & 01 & 0 & 02 \\
\hline Entrevistado 04 & 0 & 01 & 01 & 01 & 01 \\
Entrevistado 05 & 01 & 0 & 0 & 0 & 0 \\
Entrevistado 06 & 01 & 01 & 01 & 01 & 02 \\
Entrevistado 07 & 0 & 01 & 01 & 0 & 05 \\
Entrevistado 08 & 03 & 04 & 0 & 0 & 05 \\
Entrevistado 09 & 01 & 01 & 0 & 0 & 01 \\
Entrevistado 10 & 01 & 01 & 0 & 0 & 02 \\
Entrevistado 11 & 0 & 02 & 0 & 0 & 01 \\
Entrevistado 12 & 0 & 01 & 0 & 0 & 02 \\
Entrevistado 13 & 0 & 01 & 0 & 0 & 02 \\
Total & $\mathbf{0 9}$ & $\mathbf{2 0}$ & $\mathbf{0 5}$ & $\mathbf{0 3}$ & $\mathbf{2 8}$
\end{tabular}

Fonte: Elaborados autores 2019.

É visível que nas percepções dos funcionários sentidos como visão, paladar e olfato são mais suscetíveis a sua percepção, dessa forma, é perceptível que o grande desafio para a gastronomia da ILPIs onde foi realizado essa pesquisa, dentro do contexto da disfagia e os cinco sentidos, é ainda elevar na alimentação a percepção do tato e a audição, a forma espessada e sem textura da comida nem sempre é agradável, é o tato que corresponde à recepção dos estímulos mecânicos, no caso dos alimentos o tato com a língua é muito importante para a definição do alimento. É através desse sentido que percebemos consistência, a textura" (ARAUJO, 2003). Os receptores do tato estão dispostos na língua e nos lábios, e junto com a audição pode vim a substituir a visão já que juntos constroem informações sobre textura, forma, peso e temperatura, alimentos viscosos e gelatinosos podem gerar percepções negativas para esses sentidos mesmo que atendam as expectativas visuais (ARAUJO, 2009). 
Bom, pegando o exemplo de um hóspede, estamos passando por um caso recente, com certeza sim a textura, ela faz bastante diferença. $O$ hóspede pedindo um pedaço de carne para comer, faz recentemente um mês que ele tá na alimentação pastosa faz bastante falta a textura" (ENTREVISTADO(a), 03).

Mesmo assim, outros entrevistados contam que é possível suprir a necessidade de textura com o sabor, com molhos que realçam esse sabor, e que esse processo é mais incomodo no início da alimentação pastoso.

[...] somos acostumados a comer uma comida diferente uma textura mais dura e de uma hora para outra, eles vão ter que comer uma comida mais mole isso causa impacto, até ela se acostumar vai ser um pouco demorado, depois que ela se acostuma ela não vai reclamar mais e nem vai sentir falta (ENTREVISTADO(a), $01)$.

Ainda sobre a textura outro relato levantou importância novamente do histórico alimentar dos hóspedes e de como pode ajudar a ultrapassar essa barreira.

A textura pastosa traz interferência na recordação, mais eu acho que a gente também
tem limitações impostas pelas realidade concreta, se eu tenho um paciente que não
tem condições de comer uma batata crocante eu não vou poder mais dar essa bata
crocante, mais isso não quer dizer eu não podemos encontrar nesse recordatário
alimentar algo que lhe de muito prazer como a batata crocante mais tinha uma
história de um outro sabor que também me faz feliz a gente vive limitações na vida
Uesley, ne o idoso também (ENTREVISTADO(a), 06).

Com relação ao sentido da audição como já relatado destacou-se o quanto o ruído do ambiente interfere na alimentação dos hóspedes, ou seja, o excesso de sons, barulho no ambiente hospitalar, além de afetar a audição, interfere no bem-estar físico e emocional, diminuindo consecutivamente o próprio apetite, levando o idoso ao desinteresse pela alimentação (LIMA et al., 2014). De acordo com Araújo (2009) "Os sons emitidos na mastigação e na deglutição caracterizam os alimentos", por se tratar de uma alimentação pastosa, foram observadas que as texturas são muito sutis e o ruído ambiente dificulta sua percepção.

Muito barulho, acho que é isso muita conversa tira atenção deles na comida, e eles ficam prestando atenção em outra coisa" (ENTREVISTADO(a), 02).

O nosso ambiente aqui, ainda no momento, encontra-se menor que o necessário, está apertado, muitos hospedes e poucos lugares e barulho né, ainda falta treinamento a respeito disso, de manter o silencio e se falar somente o necessário" (ENTREVISTADO(a), 04).

Ruído, a cultura do ruído, que é uma coisa que existe não só aqui, as vezes quando se tem um idoso silencioso, vamos entrar por outra caminho, o caminho da linguagem, a pessoa não suporta o silencio e ela fala por ela e pelo idoso, tem muito ruído, o próprio ruído ambiental que interfere, e ai eu digo dede aquele ruído da televisão de gente entrando e saindo, o próprio ruído de bater do talher, o fato de ser um local de passagem de funcionário de familiar de não ser um ambiente de ter uma certa reserva acho que isso também atrapalha. Acho que também atrapalha um pouco diferentes graus de comprometimento no mesmo ambiente ou na mesma 
mesa, tem que ter momentos diferentes para alimentar pacientes com grau de disfagia diferentes, principalmente para quem tem alteração de comportamento (ENTREVISTADO(a) 06)

Dessa forma, o procedimento correto como observado nos relatos anteriores é o treinamento de conduta na hora da refeição, onde o idoso é o único foco, afinal o contato com outras pessoas e companhia de outros hóspedes é fundamental para o sentir-se a mesa do paciente disfágico (SOUZA et al., 2003).

É importante que a pessoa idosa possa ter companhia nas refeições. Sentar confortavelmente à mesa em companhia de outras pessoas, sejam elas da família, amigos ou o próprio cuidador, proporciona mais prazer com a alimentação e favorece o apetite. A falta de companhia na alimentação acaba contribuindo para que a pessoa idosa tenha menos preocupação com o tipo de alimento consumido e a tendência, nessa situação, é alimentar-se de maneira inadequada tanto do ponto de vista da qualidade, como da quantidade (BRASIL, 2007: 18).

Todavia, existem realidades onde torna-se necessário que a alimentação do idoso com disfagia seja realizada separadamente de maneira isolada, onde o silêncio venha a ajudar a percepção das respostas motoras, ou seja, a limitação orgânica nesse caso se sobrepõe ao social, podendo a conduta de sociabilidade ser realizada em outro momento (MYRIAN NAJAS, 2011).

Por fim, o contexto no qual o alimento que se apresentava ao paciente, a "papa pastosa" - figura 2, e as suas dimensões ocultas, é passado no cardápio de comidas pastosas da instituição. Contudo os alimentos que não correspondem àquilo que realmente são: escalopes ou pedaços de carne reconstituídos, batidos e processados sem forma, texturas muitas vezes não favoráveis, matérias primas nas quais só sobrou o nome (CORBEAU, 2005), ainda fazem parte da realidade na ILPI, ficando claro nos relatos que é preciso buscar além do visual das cores às formas do alimento.

[...] tentar buscar um visual parecido com certeza vai fazer com que a aceitação seja melhor, dá pra ir muito além, estamos pesquisando coisas aqui na instituição e está muito próximo de fazer pouco além do que a gente já faz, utilização de bicos, fazer uns formatos diferente, utilizando materiais da gastronomia molecular, novos materiais sendo introduzidos, e os formatos que estamos pesquisando estamos perto de ir além (ENTREVISTADO(a), 04).

Mesmo assim é claro o avanço referente as percepções dos cinco sentidos, com a nova alimentação e de como tal procedimento mudou a rotina do ILPIs.

Era uma alimentação que precisa de alguma intervenção, porque ainda existia uma noção que existem muitos outros residenciais da grande Florianópolis de que estando batido é o que ele necessita, aí assim encontrava muitas vezes alimentos diferente misturados sem sabor, cor inadequada difícil tanto pra quem oferta quanto pra quem come saber o que estava comendo, se formos pensar o quesito se a comida era atrativa ou não, não, não era atrativa (ENTREVISTADO(a), 06). 
A pessoa idosa hospitalizada na ILPIs retratada na pesquisa fornece um claro exemplo de que "a geração que ama cozinhar para melhor identificar as matérias-primas que transforma" (CORBEAU, 2005: 234), hoje encontra a possibilidade de comer, escolher e sentir satisfação nesse processo.

\section{CONSIDERAÇÕES FINAIS}

Previamente as demais considerações finais dessa pesquisa, é importante relatar que a inspiração para a realização de um estudo onde estivessem envolvidos: disfagia, gastronomia hospitalar e gastronomia geriátrica, surgiram com as primeiras leituras onde se destacou a falta de envolvimento de profissionais da área nesse setor. A gastronomia se tornou um mercado de luxo, e talvez por causa disso a maioria dos profissionais tenham negligenciado outros campos de trabalho, que não seja, no glamour de um restaurante.

Acredita-se que o presente trabalho atingiu o objetivo de analisar através da visão dos funcionários de uma ILPIs, as percepções dos cinco sentidos em pacientes com disfagia. Sobre a fundamentação teórica tentou se entender as doenças que acompanham a senescência e por sua vez podem a vim causar a disfagia, bem como toda a mudança alimentar e sensorial que esses problemas acarretam. Com relação a análise de dados é importante ressaltar que apesar do objetivo focar todos os cinco sentidos, sentidos como paladar/gustação, visão e olfato receberam maior destaque nas percepções realizadas pelos funcionários da ILPIs, sentidos como audição e tato muitas vezes sequer foram citados, isso vai de encontro a dificuldade do autor desse artigo de encontrar fundamentação bibliográfica que referisse os sentidos da audição e tato e de que forma eles estão presentes na alimentação.

Contudo, ainda existem outros futuros desafios a serem ultrapassados na alimentação da ILPIs em questão, existe uma cultura por parte da clínica de misturar os medicamentos previamente triturados no alimento pastoso, alterando assim sabor (normalmente se tornando amargo), e fazendo com que o hóspede rejeite uma parte ou todo o alimento. Deve-se assim, tomar medidas para que isso não ocorra mais como a sugerida por Heydrich (2006), a de misturar os remédios triturados em uma solução de água espessada, evitando assim a alteração de sabor com nos alimentos e algum tipo de reação que possa resultar a mistura dos medicamentos com o alimento. Todavia essa 
mudança depende de uma ação conjunta de treinamento multidisciplinar dos setores de nutrição e enfermagem.

Outro ponto que pode ser considerado prejudicial a essa pesquisa foi o fato de muitos dos idosos envolvidos no estudo ou vieram a falecer durante o período da pesquisa ou deixaram a clínica por diversos motivos. Mesmo assim, pode-se concluir que houve tendência para o aumento da satisfação dos pacientes em relação a nova alimentação e um maior despertar de seus sentidos em relação a alimentação.

Por fim cabe destacar a importância de entender a gastronomia como ciência, como ferramenta de pesquisa, abrindo assim espaço para que novos estudos avaliem esse ou outros aspectos da gastronomia hospitalar e incentivem esta prática, porque afinal o que nos cabe na finitude da vida, onde talvez comer e resgatar lembranças sejam um dos nossos únicos prazeres como afirma MAES (2005: 239), "não importa a denominação: centro hospitalar, clínica, sanatório, casa de retiro, quando o sofrimento diminui e a dor se acalma, a refeição é um momento de trégua e evasão, impacientemente esperado".

\section{REFERÊNCIAS}

ACHILLES, Elayne. The Dysphagia Cook Book: Great tasting and nutritious recipes for people with swallowing difficulties. Naperville: Cumberland Hause Publishing, 2004. $161 \mathrm{p}$.

A FESTA de BABETTE. Direção de Gabriel Axel. Produção de Just Betzer. Intérpretes: Stéphane Audran. Roteiro: Gabriel Axel. Música: Per Norgard. Dinamarca:Spectra Filmes, 1987. (102 min.), DVD, son., color. Legendado. Oscar Melhor Filme Estrangeiro 1988.

ALVES, Leda Maria Tavares; DANTAS, Roberto Oliveira. Percepção de sabores em pacientes com acidente vascular encefálico. Revista Cefac, São Paulo, v. 13, n. 6, p.1081-1085, set. 2011. Disponível em:http://www.scielo.br/scielo.php?pid=S1516-

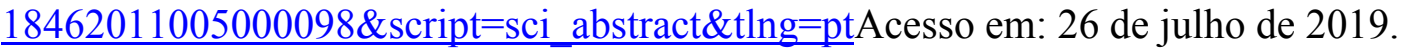

ANTUNES, Ana Claudia Guimarães et al. Respostas gastronômicas: Para dietas de indivíduos com disfagia - nutrição e gastronomia aliando o cuidado à saúde com o prazer de comer. Contexto da Alimentação: Comportamento cultura e sociedade, São Paulo, v. 1, n. 1, p.30-35, 2012. Disponível em: http://pt.slideshare.net/senacsaopaulo/revista-contextos-da-alimentao-edio-completavol-1-n-1Acesso em: 26 de julho de 2019.

ARAUJO, C. A. A vida depois dos 100. Revista Terra. nov. 2003, p. 45-57 
ARAUJO, Wilma M.c. et al (Org.). Alquimia dos Alimentos. 2. ed. Brasília: Senac, 2009. 560 p.

BARBOSA, Maira Tonidandel; CARAMELLI, Paulo. Como diagnosticar as quatro causas mais frequentes de demência? Revista Brasileira de Psiquiatria, São Paulo, v. 24, n. 1, abr. 2002. Disponível em: http://www.scielo.br/scielo.php?pid=S1516-

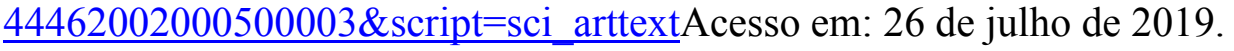

BARBEITOS, Carmo Lédna Pereira. Percepção do olfato: folhas que não guardei. Revista Ohun Ufba, Bahia, v. 6, n. 8, p.01-12, jan. 2011.Disponível em; http://www.revistaohun.ufba.br/pdf/ledna.pdf.Acesso em: 26 de julho de 2019.

BOCCANERA, Nélio Barbosa. A utilização das cores no ambiente de internação hospitalar. 2007. 95 f. Dissertação (Mestrado) - Curso de Ciências da Saúde, Universidade Federal de Goiás, Goiânia, 2007. Disponível em:

http://repositorio.unb.br/handle/10482/3751 mode=full\&submit simple=Mostrar + item +em+formato+completoAcesso em: 02 de abril de 2019.

BRASIL. MINISTÉRIO DA SAÚDE. Envelhecimento e saúde da pessoa idosa. Brasília: Ministério da Saúde, 2007. Disponível em:

http://bvsms.saude.gov.br/bvs/publicacoes/abcad19Acesso em: 26 de julho de 2019.

CASCUDO, Luís Câmara. História da Alimentação no Brasil. 3. ed. São Paulo: Global, 2004. $954 \mathrm{p}$

CALDAS, Célia Pereira. O Idoso em Processo de Demência: o impacto na família. In: COIMBRA JUNIOR, Carlos E. A.; MINAYO, Maria Cecília de Souza (Org.).

Antropologia, saúde e envelhecimento. 2. ed. Rio de Janeiro: Fiocruz, 2011. p. 51-71.

CAMPOS, Sinara Rafaela. Os cinco sentidos da hospitalidade. Observatório de Inovação do Turismo, Rio de Janeiro, v. 3, n. 1, p.01-17, mar. 2008. Disponível em: http://bibliotecadigital.fgv.br/ojs/index.php/oit/article/view/5694. Acesso em: $02 \mathrm{de}$ abril de 2019.

CANABRAVA, Francisco et al. Os sentidos da comida: Será que só a fome é o tempero do alimento? Ecletica, Rio de Janeiro, v. 1, n. 1, p.01-04, jan. 2006. Disponível em: http://puc-riodigital.com.puc-rio.br/media/1\%20\%20os\%20sentidos\%20da\%20comida.pdfAcesso em: 20 de maio de 2019.

CANESQUI,Ana Maria; GARCIA, Rosa Manda Diez. Uma introdução à reflexão sobre abordagem sociocultural da alimentação. In: CANESQUI, Ana Maria; GARCIA, Rosa Wanda Diez (Org.). Antropologia e nutrição: um diálogo possível. Rio de Janeiro: Fiocruz, 2005. p.09-19. Disponível emhttp://books.scielo.org/id/v6rkd Acesso em: 20 de abril de 2019.

CARDOSO, Elisabeth et al. Gastronomia Hospitalar para Pacientes em Situação Especiais: Cardiologia e pneumologia. São Paulo: Atheneu, 2014. 230 p. 
CÁRDENAS, Carmen Jansen de; SILVA, Valcilene Pinheiro da. A comida e a sociabilidade na velhice. Revista Kairós, São Paulo, v. 10, n. 1, p.51-69, jun. 2007. Disponível em: http://revistas.pucsp.br/index.php/kairos/article/view/2573Acesso em: 26 de abril de 2019.

CARNEIRO, Henrique. Comida e sociedade: uma história da alimentação. Rio de Janeiro: Campus, 2003. p. 1

CARVALHO, Cecília Maria Resende Gonçalves de; TAVARES, Thaíza Estrela. Características de mastigação e deglutição na doença de alzheimer. Revista Cefac, São Paulo, v. 14, n. 1, p.122-137, fev. 2012. Disponível em:

http://www.scielo.br/pdf/rcefac/v14n1/110-10Acesso em: 09 de maio de 2019.

CATTANI, Roceli Brum; GIRARDON-PERLINI, Nara Marilene Oliveira. Cuidar do idoso doente no domicílio na voz de cuidadores familiares. Revista Eletrônica de Enfermagem, Goiás, v. 06, n. 02, jan. 2004. Disponível em:

https://www.fen.ufg.br/fen_revista/revista6_2/idoso.htmlAcesso em: 21 de maio de 2019.

CAVALCANTI, Hannalice Gottschalck. Disfagia orofaríngea de origem neurológica em adulto. 1999. 46 f. Monografia (Especialização) - Curso de Fonodiologia, Centro de Especialização em Fonoaudiologia Clínica Motricidade Oral, Fortaleza, 1999.

Disponível em: https://docplayer.com.br/5040137-Disfagia-orofaringea-de-origemneurologica-em-adulto.htmlAcesso em: 10 de junho de 2019.

CHAIMOWICZ Flavio. A saúde dos idosos brasileiros as vésperas do século XXI: problemas, projeções e alternativas. Revista de saúde pública. São Paulo, v. 31, n. 2 , p.184-200, abr. 1997

CHIARI, Brasília Maria; BOMFIM, Fernanda Maria Santana; ROQUE, Francelise Pivetta. Descrição da dinâmica de alimentação de idosas institucionalizadas. Rev Soc Bras Fonoaudiologia, São Paulo, v. 15, n. 2, p.256-263, fev. 2010. Disponível em: http://www.scielo.br/pdf/rsbf/v15n2/18.pdfAcesso em: 24 de maio de 2019.

CHIAVENATO, Idalberto. Recursos Humanos. 5 ed.São Paulo: Atlas, 1998.

CORBEAU, Jean-pierre. Alimentar-se no Hospital: as dimensões ocultas da comensalidade. In: CANESQUI, Ana Maria; GARCIA, Rosa Wanda Diez (Org.). Antropologia e nutrição: um diálogo possível. Rio de Janeiro: Fiocruz, 2005. p. 227238. Disponível em: http://books.scielo.org/id/v6rkdAcesso em: 26 de julho de 2019.

COLARES, Fernanda Cristina de Jesus et al. Alterações gustativas no envelhecimento. Revista Kairós, São Paulo, v. 1, n. 11, p.217-235, jun. 2008. Disponível em: http://revistas.pucsp.br/index.php/kairos/article/view/2518Acesso em: 26 de julho de 2019.

FACHIN, Odília. Fundamentos de Metodologia. 5. ed. São Paulo: Saraiva, 2006. FREITAS, Ana Karina Miranda de. Psicodinâmica das cores em comunicação. Nucon, Limeira, v. 12, n. 04, p.01-18, out. 2007. Disponível em: 
http://www.iar.unicamp.br/lab/luz/ld/Cor/psicodinamica_das_cores_em_comunicacaoA cesso em: 18 de março de 2019.

FURKIM, Ana Maria; SACCO, Andréa Baldi de Freitas. Eficácia da fonoterapia em disfagia neurogênica usando a escala funcional de ingestão por via oral (fois) como marcador. 10. ed. Eficácia da fonoterapia em disfagia. Revista CEFAC, São Paulo, v.10, n.4, 503-512, out-dez, 2008

GATTO, Ana Rita. Efeito do sabor azedo e da temperatura fria na fase oral da deglutição no acidente vascular encefálico. 2010. 91 f. Dissertação (Mestrado) - Curso de Medicina, Faculdade de Medicina de Botucatu Unesp,, Botucatu, 2010. Disponível em: https://repositorio.unesp.br/handle/11449/86302Acesso em: 26 de julho de 2019.

GIL, Antonio Carlos. Como Elaborar Projetos de Pesquisa. 4. ed. São Paulo: Atlas, 2002. $176 \mathrm{p}$.

GIL, Antonio Carlos. Métodos e técnicas de pesquisa social. 6. ed. São Paulo: Atlas, 2008. 200 p.

GODOY, Arilda Schmidt. Introdução à pesquisa qualitativa e suas possibilidades: Uma revisão histórica dos principais autores e obras que refletem esta metodologia de pesquisa em Ciências Sociais. Revista de Administração de Empresas, São Paulo, v. 35, n. 2, p.57-63, mar. 1995. Disponível em:

http://www.scielo.br/pdf/rae/v35n2/a08v35n2.pdfAcesso em: 24 de maio de 2019.

GOMEZ, Jacqueline Abrisqueta. Memória e envelhecimento cognitivo saudável. In: FUENTES, Daniel; DINIZ, Leandro F. Malloy; COSENZA, Ramon M. (Org.). Neuro psicologia do envelhecimento: Uma abordagem multidimensional. Porto Alegre:

Artmed, 2013. p. 171-180

He, Wan; Daniel Goodkind, Daniel; Kowal, Paul. U.S. Census Bureau, International Population Reports, P95/16-1, An Aging World: 2015, Editora: U.S. Government Publishing Office, Washington, DC, 2016.

HEYDRICH, Joana. Padrão de prescrição, preparo e administração de medicamentos em usuários de sondas de nutrição enteral internados em um hospital universitário. 2006. 108 f. Dissertação (Mestrado) - Curso de Ciências Farmacêuticas, Universidade Federal do Rio Grande do Sul, Porto Alegre, 2006. Disponível em:http://www.lume.ufrgs.br/bitstream/handle/10183/8210/000570672.pdf? sequence=1 Acesso em: 24 de maio de 2019.

JESUS, Camila Corrêa de et al. Anormalidades sensoriais: olfato e paladar. Arquivos Int. Otorrinolaringologia, Belém, v. 23, n. 3, p.350-358, jul. 2011. Disponível em: http://www.scielo.br/scielo.php?pid=S180948722011000300014\&script=sci arttextAcesso em: 26 de julho de 2019. LAGES, Priscilla Ceci; RIBEIRO, Rita de Cássia; SOARES, Luciana Santos. A gastronomia como proposta de qualificação pastosas: análise, intervenção e avaliação dietética das refeições hospitalares. Nutrição e Alimentação, Araraquara, v. 24, n. 1, p.93-99, jan. 2013. 
LEWIS, Kim Corbin; LISS, Julie M.; SCIORTINO, Kellie L. (traduzido por Koriun Traduções.). Anatomia clínica e fisiologia do mecanismo de deglutição. São Paulo: Cengage Learning, 2009. 281 p.

LÉVI-STRAUSS Claude. O cru e o cozido. São Paulo: Cosac \& Naify; 2004.

LIMA, Deise Feijó et al. Avaliação dos fatores que dificultam a alimentação de idosos hospitalizados. Revista Rene, Curitiba, v. 15, n. 04, p.78-84, jul. 2014. Disponível em: http://www.periodicos.ufc.br/rene/article/view/1071 Acesso em: 11 de abril de 2019.

LIMA, Juvenete Pereira. A influência das alterações sensoriais na qualidade de vida do idoso. Revista Científica Eletrônica de Psicologia, São Paulo, v. 8, n. 5, maio 2007. Disponível em:

http://faef.revista.inf.br/imagens_arquivos/arquivos_destaque/SgxfdPCyrRBz4HS 2013 -5-10-16-11-50.pdfAcesso em: 12 de maio de 2019.

Lima-Costa, M. Fernanda; Andrade, Fabíola Bof de; Souza Jr., Paulo Roberto Borges de; Neri, Anita Liberalesso; Duarte, Yeda Aparecida de Oliveira; Castro-Costa, Erico; Oliveira, Cesar de. Socio economic inequalities in activities of daily living limitations and in the provision of informal and formal care for non institutionalized older Brazilians: National Health Survey, 2013. International Journal for Equity in Health, $\mathrm{v}$ 15, n 1, 2016. Disponível em:

https://www.ncbi.nlm.nih.gov/pmc/articles/PMC5112736/ Acesso em 26 de julho de 2019.

Lima-Costa, M. Fernanda; Andrade, Fabíola Bof de; Souza Jr., Paulo Roberto Borges de; Neri, Anita Liberalesso; Duarte, Yeda Aparecida de Oliveira; Castro-Costa, Erico; Oliveira, Cesar de.The Brazilian Longitudinal Study of Aging (ELSI-Brazil): Objectives and Design American Journal of Epidemiology, v.187, n.7, July 2018, Pages 13451353, https://doi.org/10.1093/aje/kwx387Acesso em: 10 de julho de 2019.

MACIEL, Maria Eunice. Cultura e alimentação ou o que têm a ver os macaquinhos de Koshima com Brillat-Savarin?. Horizontes Antropológicos, Porto Alegre, ano 7, n. 16, p. 145-156, dezembro de 2001. Disponível em:

http://www.scielo.br/scielo.php?pid=S010471832001000200008\&script $=$ sci abstractAcesso em: 10 de abril de 2019.

MACIEL, Maria Eunice. Identidade Cultural e Alimentação. In: CANESQUI, Ana Maria; GARCIA, Rosa Wanda Diez (Org.). Antropologia e nutrição: um diálogo possível. Rio de Janeiro: Fiocruz, 2005. p. 49-55. Disponível em: http://books.scielo.org/id/v6rkdAcesso em: 14 de junho de 2019.

MAES Gérard. A Sopa no Hospital: testemunho. In: CANESQUI, Ana Maria; GARCIA, Rosa Wanda Diez (Org.). Antropologia e nutrição: um diálogo possível. Rio de Janeiro: Fiocruz, 2005. p. 227-238. Disponível em:

http://books.scielo.org/id/v6rkdAcesso em: 20 de maio de 2019.

MAGALHÃES, Lara Margarida Ribeiro. Relação entre saúde oral e nutrição em idoso. 2011. 49 f. Dissertação (Mestrado) - Curso de Medicina Dentaria, Universidade 
Fernando Pessoa, Porto, 2011. Disponível em:

http://bdigital.ufp.pt/bitstream/10284/2402/3/T.pdfAcesso em: 30 de abril de 2019 .

MALAGELADA, J.r. et al. World Gastroenterology Organisation Practice Guidelines: Disfagia. 2004,13 p.

MELO, Graça. Apoio ao doente no domicílio. In A doença de Alzheimer e outras demências em Portugal. Lisboa: Lidel. 2005.

MOUSSALLE, Sergio et al. Guia prático de otorrinolaringologia: anatomia, fisiologia e semiologia. Porto Alegre: Edipucrs, 1997. 165 p.

MONTEIRO, Marlene Azevedo Magalhães. Percepção sensorial dos alimentos em idosos. Espaço Para A Saúde, Londrina, v. 10, n. 2, p.34-42, jun. 2009. Disponível em: https://docplayer.com.br/5893863-Percepcao-sensorial-dos-alimentos-emidosos.htmlAcesso em: 15 de abril de 2019.

MYRIAN NAJAS (Org.). $1^{\circ}$ consenso brasileiro de nutrição e disfagia em idosos hospitalizados. Barueri: Manole, 2011. 106 p.

NAKASATO, Miyoko et al. A Gastronomia Hospitalar como Instrumento de Humanização. In: Anais do Congresso Internacional de Humanidades \& Humanização em Saúde, n.2, v.1. 2014. São Paulo. Proceedings...São Paulo: Editora Blucher, 2014. Disponível em: http://www.proceedings.blucher.com.br/article-details/a-gastronomiahospitalar-como-instrumento-de-humanizao-9493 Acesso em: 26 de abril de 2019.

NETO Miranda. Pesquisa para o planejamento: Métodos \& Técnicas. Rio de Janeiro: Fgv, 2005. $87 \mathrm{p}$

OLIVEIRA, Mariana Mendonça Greghi et al. Terapia nutricional em disfagia: a importância do acompanhamento nutricional. Revista Brasileira de Ciências da Saúde, São Paulo, VI, n.16 , p.71-76, 2008. Disponível em:

https://seer.uscs.edu.br/index.php/revista_ciencias_saude/article/view/382Acesso em: 04 de maio de 2019.

OLIVEIRA, Renata Borba de Amorim; VERAS, Renato Peixoto; PRADO, Shirley Donizete. O fim da linha"? Etnografia da alimentação de idosos institucionalizados reflexões a partir das contribuições metodológicas de Malinowski. Revista Brasileira de Geriatria e Gerontologia, Rio de Janeiro, v. 13, n. 1, p.133-143, jan. 2010. Disponível em: http://www.scielo.br/scielo.php?script=sci arttext\&pid=S1809-

98232010000100014Acesso em: 15 de julho de 2019.

PADOVANI, Aline Rodrigues et al. Protocolo fonoaudiológico de avaliação do risco para disfagia (PARD). Revista da Sociedade Brasileira de Fonoaudiologia, Set 2007, vol.12, no.3, p.199-205.

PAGNO, Carlos Henrique. Desenvolvimento de espessante alimentar para líquidos com valor nutricional agregado, destinado a individuos disfágicos. 2009. 84 f. Dissertação (Mestrado) - Curso de Ciências e Tecnologia de Alimentos, Universidade Federal do Rio Grande do Sul, Porto Alegre, 2009. 
PASSOS, Darlise Rodrigues dos. Avaliação do paladar de idosos e sua relação com o estado nutricional. 2010. 51 f. TCC (Graduação) - Curso de Nutrição, Universidade Federal do Rio Grande do Sul, Porto Alegre, 2010. Disponível em: https://lume.ufrgs.br/handle/10183/28186Acesso em: 20 de julho de 2019.

PIVI, Glaucia Akiko Kamikado; SCHUULTZ, Todrigo Rizek; BERTOLUCCI, Paulo Henrique Ferreira. Nutrição em demência: uma abordagem criteriosa do diagnóstico do estado nutricional e das medidas utilizadas para sua preservação e recuperação nas demências. São Paulo: Scio, 2013. 238 p.

RODRIGUES, Rosalina A. P.; DIOGO, Maria José D. (Org.). Como cuidar dos idosos. 4.ed. São Paulo: Papirus, 2004.

SANTAELLA, Lucia. Matrizes da linguagem e pensamento: sonora, visual, verbal, aplicações na hipermídia. 3. ed. São Paulo: Iluminuras, 2005. 435 p.

SILVA, Daniel Marques da; BATOCA, Ernestina Maria Veríssimo. O conhecimento científico e a enfermagem. Millenium, Visel, v. 27, n. 1, abr. 2003. Disponível em: http://www.ipv.pt/millenium/Millenium27/13.htm Acesso em: 02 de junho de 2019.

STEIMBERG, Carla; FRAZÃO, Yasmin Salles; FURKIM, Ana Maria. Disfagia no Brasil: a construção de uma prática. Revista CEFAC, São Paulo, v. 5, n. 2, p. 117-125, 2003.

SAVARIN, Brillat A. A Fisiologia do Gosto. São Paulo. ed. cia. das letras. 1995.

SANTOS, Vanice dos; CANDELORO, Rosana J. Trabalhos acadêmicos: uma orientação para pesquisa e normas técnicas. Porto Alegre: Age, 2006. 77 p

SÁ, Sumaia Midlej Pimental; RABINOVICH, Elaine Pedreira. Compreendendo a família da criança com deficiência física. Revista Brasileira de Crescimento e

Desenvolvimento Humano, São Paulo, v. 16, n. 1, abr. 2006. Disponível em: http://pepsic.bvsalud.org/scielo.php?script $=$ sci arttext\&pid=S010412822006000100008Acesso em: 25 de julho de 2019.

SILVA, Ana Lúcia Neves Duarte da et al. Análise da assistência nutricional a pacientes disfágicos hospitalizados na perspectiva de qualidade. O Mundo da Saúde, São Paulo, v. 33, n. 3, p.310-319, 09 jun. 2009.

SCHLINDWEIN-ZANINI, Rachel. Demência no idoso: aspectos neuropsicológicos. Revista Neurociências, Florianópolis, v. 2, n. 18, p.220-226, 2010. Disponível em:

http://www.revistaneurociencias.com.br/edicoes/2010/RN1802/262\%20revisao.pdfAces so em: 26 de julho de 2019.

SCHIFFMAN, Susan S.. Critical illness and changes in sensory perception. Proceedings Of The Nutrition Society, Durham, n. 66, p.331-345, jan. 2007. Disponível em: $<$ https://www.cambridge.org/core/journals/proceedings-of-the-nutritionsociety/article/critical-illness-and-changes-in-sensory- 
perception/B23E514E690452A358BC9BBDA6B28EFBAcesso em: 26 de julho de 2019.

SIQUEIRA, Renata Lopes de; BOTELHO, Maria Izabel Vieira; COELHO, France Maria Gontijo. A velhice: algumas considerações teóricas e conceituais. Ciência \& Saúde Coletiva, Rio de Janeiro, v. 7, n. 4, p.899-906, jan. 2002. Disponível em: http://www.scielo.br/scielo.php?pid=S1413-

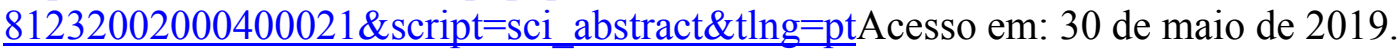

SOUSA, Ângela Maria Alves e et al. Observação participante na pesquisa qualitativa: conceitos e aplicações na área da saúde. Enferm Uerj, Rio de Janeiro, v. 2, n. 15, p.276283, maio 2007. Disponível em: http://www.facenf.uerj.br/v15n2/v15n2a19.pdfAcesso em: 28 de maio de 2019.

SOUZA, Beatriz B. Alvez de et al. Nutrição e disfagia: Guia para profisssionais. Curutiba: Nutroclinica, 2003. 60 p.

SOUZA, Mariana Delega de; NAKASATO, Miyoko. A gastronomia hospitalar auxiliando na redução dos índices de desnutrição entre pacientes hospitalizados. $O$ Mundo da Saúde, São Paulo, v. 2, n. 35, p.208-214, mar. 2011. Disponível em: http://www.saocamilo-sp.br/pdf/mundo_saude/84/208-214.pdfAcesso em: 26 de julho de 2019.

SUZUKI, Heloisa Sawada. O entardecer da deglutição: Um estudo sobre modificações nos hábitos da rotina alimentar x fisiologia da deglutição do idoso normal. 1996. $40 \mathrm{f}$. Monografia (Especialização) - Curso de Motricidade Oral, Centro de Especialização em Fonoaudiologia Clínica Motricidade Oral, São Paulo, 1997. Disponível em: http://docplayer.com.br/35348497-O-entardecer-da-degluticao-um-estudo-sobremodificacoes-nos-habitos-da-rotina-alimentar-x-fisiologia-da-degluticao-do-idosonormal.htmlAcesso em: 14 de maio de 2019.

UNITED NATIONS, Department of Economic and Social Affairs, Population Division. World Population Prospects: The 2015 Revision, 2016. Disponível em: http://esa.un.org/unpd/wpp/. Acesso em: 27 de julho de 2019.

Recebido 15/10/2019

Aprovado 11/12/2019 